\section{La red molinar de la Sierra Morena occidental a finales del siglo XV}

\author{
The mill network of the western Sierra Morena \\ in the late fifteenth century
}

\author{
José Damián González-Arce \\ Universidad de Murcia, España \\ josedam@um.es \\ (iD) 0000-0002-3296-0554
}

Información del artículo:

Recibido: 20 enero 2020

Revisado: 6 noviembre 2020

Aceptado: 28 diciembre 2020

ISSN $\quad 2340-8472$

ISSNe 2340-7743

DOI $\quad 10.17561 /$ AT.18.5230

(c) $\mathrm{CC}-\mathrm{BY}$

\section{RESUMEN}

El presente trabajo tiene como cometido reconstruir la red molinar que se formó a finales del sigloXV enla actual comarca de la Sierra de Aracena, conocida entonces como Sierra de Aroche. Se trata de un conjunto excepcional de más de 250 ingenios, que sólo se explica por las características del medio natural donde se radicaron. Además, para tal reconstrucción, a través de 13 mapas, realizados gracias a una serie de informes redactados en la época sobre tales instalaciones, ha sido vital contar con multitud de datos toponímicos presentes en ellos. Las conclusiones y la información que aporta este análisis, abren muchas posibilidades de estudio en ámbitos relativos al crecimiento económico y demográfico, así como a las relaciones sociales en esta comarca.

PALABRAS CLAVE: Molinos hidráulicos, Red fluvial, Orografía, Toponimia, Sierra de Aracena, Siglo XV.

\section{ABSTRACT}

The present work has the task of reconstructing the mill network that was formed at the end of the 15th century in the current region of the Sierra de Aracena, then known as Sierra de Aroche. It is an exceptional set of more than 250 mills, which can only be explained by the characteristics of the natural environment where they were located. Moreover, for such reconstruction, through 13 maps, made thanks to a series of reports written at the time on such facilities, it has been vital to have a multitude of toponymic data present in them. The conclusions and information provided by this analysis open up many possibilities for study in areas related to economic and demographic growth, as well as social relations is in the region.

KEYWORDS: Hydraulic mills, River network, Orography, Toponymy, Sierra de Aracena, XV century

(C) Universidad de Jaén (España). Seminario Permanente Agua, Territorio y Medio Ambiente (CSIC) 


\section{A rede de moagem da Serra Morena ocidental no final do século XV}

\section{SUMÁRIO}

O objetivo deste trabalho é reconstruir a rede de moinhos formada no final do século XV na atual região da Serra de Aracena, então conhecida como Serra de Aroche. É um grupo excepcional de mais de 250 moinhos, o que só pode ser explicado pelas características do ambiente natural onde se estabeleceram. Além disso, para tal reconstrução, através de 13 mapas, feitos graças a uma série de relatórios escritos na época sobre tais instalações, era vital ter uma infinidade de dados toponímicos presentes neles. As conclusões e informações fornecidas por essa análise abrem muitas possibilidades de estudo em áreas relacionadas ao crescimento econômico e demográfico, bem como às relações sociais nessa região.

PALAVRAS-CHAVE: Moinhos hidráulicos, Rede fluvial, Orografia,

Toponímia, Sierra de Aracena, Século XV.

\section{Le réseau de moulins de la Sierra Morena occidentale à la fin du XV siècle}

\section{RÉSUMÉ}

Le but de ce travaux est de reconstruire le réseau de moulins formé à la fin du XVe siècle dans la région actuelle de la Sierra de Aracena, alors connue sous le nom de Sierra de Aroche. C'est un groupe exceptionnel de plus de 250 moulins, qui ne s'explique que par les caractéristiques du milieu naturel où ils se sont installés. De plus, pour une telle reconstruction, à travers 13 cartes, réalisées grâce à une série de rapports élaborés à l'époque sur ces installations, il était vital de disposer d'une multitude de données toponymiques. Les conclusions et les informations fournies par cette analyse ouvrent de nombreuses possibilités d'étude dans des domaines liés à la croissance économique et démographique, ainsi qu'aux relations sociales dans cette région.

MOTS CLÉS: Moulins hydrauliques, Réseau fluvial, Orographie, Toponymie, Sierra de Aracena, XV siècle.

\section{La rete molitoria della Sierra Morena occidentale alla fine del XV secolo}

\section{SOMMARIO}

Lo scopo di questo lavoro è quello di ricostruire la rete del mulino che si è formata alla fine del XV secolo nell'attuale regione della Sierra de Aracena, allora conosciuta come Sierra de Aroche. È un gruppo eccezionale di oltre 250 mulini, che può essere spiegato solo dalle caratteristiche dell'ambiente naturale in cui si sono stabiliti. Inoltre, per tale ricostruzione, attraverso 13 mappe, realizzate grazie a una serie di rapporti scritti all'epoca su tali strutture, è stato vitale avere una moltitudine di dati toponimici presenti in esse. Le conclusioni e le informazioni fornite da questa analisi aprono molte possibilità di studio in settori legati alla crescita economica e demografica, nonché alle relazioni sociali in questa regione.

PAROLE CHIAVE: Mulini idraulici, Rete fluviale, Orografia, Toponomastica, Sierra de Aracena, XV secolo. 


\section{Introducción}

Tras la conquista de mediados del siglo XIII, Sevilla recibió en diferentes períodos de los monarcas castellanos numerosas villas y lugares, que, si bien contaron con concejos apartados, quedaron bajó su jurisdicción, a modo de protectorado. Este extenso territorio del antiguo reino hispalense, que ocupaba buena parte de las actuales provincias de Sevilla, Huelva y el sur de Badajoz y llamado tierra de Sevilla, o pueblos de Sevilla, le fue entregado a la capital junto con la mayor parte de sus rentas. Las cuales fueron agrupadas en los denominados almojarifazgos, o régimen conjunto de tesorería, con los antiguos impuestos y derechos pertenecientes a los gobernantes musulmanes en cada localidad. Todos estos ingresos fiscales habían pasado a los reyes castellanos y éstos los cedieron al consistorio municipal sevillano ${ }^{1}$.

En 1491 y 1497 el concejo hispalense realizó unas pesquisas para averiguar qué derechos poseía en dichos almojarifazgos ${ }^{2}$. Entre ellos había tributos sobre instalaciones inmuebles dedicadas a actividades económicas; que en ocasiones son descritas por los testigos deponentes, interrogados al respecto, con bastante lujo de detalles, relativos a su propiedad, ubicación, antigüedad y características. Sobre todo, las radicadas en la actual Sierra de Aracena y Picos de Aroche.

Este territorio en la zona más occidental de Sierra Morena, al norte de la provincia de Huelva (Andalucía) y sur de la de Badajoz (Extremadura), agrupa los municipios de Alájar, Almonaster la Real, Aracena, Aroche, Castaño del Robledo, Corteconcepción, Cortegana, Cortelazor, Cumbres de Enmedio, Cumbres de San Bartolomé, Cumbres Mayores, Encinasola, Fuenteheridos, Galaroza, Hinojales, Jabugo, Linares de la Sierra, Los Marines, La Nava, Puerto Moral, Santa Ana la Real y Valdelarco (Mapa 1). Esta área está muy influida por los vientos húmedos atlánticos $\mathrm{y}$, por tanto, con un alto nivel pluviométrico (entre 700-900 mm anuales), que se traduce en la abundancia de cursos de agua, entre ellos los ríos Múrtigas (o Múrtiga), Odiel y Chanza, y la rivera de Huelva; los cuales discurren entre pendientes suaves, grandes valles y barrancos encajados.

Estas características permitieron la erección en estas montañas de muchos inmuebles hidráulicos, que pretendo localizar en el entorno espacial en el que se edificaron, para así analizar la tupida red que constituyeron, dado su elevado número ${ }^{3}$. Para ello, presento

\footnotetext{
1. González Arce, 2020b. Sobre estos aspectos relativos las sierras de Aracena y Aroche, Pérez-Embid Wamba, 1998.

2. González Arce, 2020a y 2020b; las referencias documentales concretas aparecen al pie de cada mapa.

3. Para otras redes molinares, Moreno Lázaro, 2018.
}

trece mapas que recogen los artefactos según los cursos de agua en los que se encontraban, intentando, en la medida de lo posible, cuando lo permita la documentación, determinar la posición relativa que ocuparon, así como el lugar o paraje concreto donde se radicaron. Es un ejercicio a medio camino entre la toponimia, la orografía y la historia social y económica del entorno rural bajomedieval. En tales mapas se incluyen molinos harineros (M), molinos batanes (B) y azudes o heridos (H) sitos en diferentes cauces fluviales, identificados por el nombre del propietario -si no consta éste, el de su mujer o herederos-, y entre paréntesis, de tenerlo, el del inmueble, así como su situación o topónimo del lugar.

Son muy escasos los trabajos de la historiografía de la Castilla medieval sobre la actividad de los molinos hidráulicos. Destacan entre ellos las obras recogidas en la bibliografía de Bueno Hernández (2012), Luis Corral (1996), Pérez Moreno (2019), Córdoba de la Llave (1990; 1993; 2002) y Sánchez Jiménez (2015), estas dos últimas sobre aspectos técnicos. Para publicaciones de otros períodos y espacios, de carácter económico, véase a Maluquer de Motes (1982); y, sobre cuestiones antropológicas, Oliver Narbona (1983).

\section{Aracena}

Situada a $673 \mathrm{~m}$ de altitud, es una de las localidades más elevadas de las incluidas en el presente trabajo, por lo que, también, es de las que mayor pluviosidad registra. Lo que, unido a su orografía accidentada y con fuertes pendientes, permitió que contase con mayor número de instalaciones molinares que las restantes.

En las pesquisas de 1497 aparecen para esta villa sus ingenios, en su mayor parte, ordenados y agrupados por cauces fluviales, o por las aldeas en la que se encontraron. Incluso se redactaron dos específicas para sendas aldeas: Galaroza e Hinojales, como veremos. Aunque hay inmuebles que no se hallaban en los cursos de agua en los que están contenidos, sino en otros diversos. Los informes de 1491 son mucho menos completos, con menos ingenios. Varias de las instalaciones están presentes en los dos años; pero otras solamente aparecen en uno de ellos, como las del arroyo de los Molinos, que sería la parte final del arroyo de la Fuente del Rey.

\section{Arroyo de la Fuente del Rey}

La Fuente del Rey es hoy un manantial seco por la afección de sondeos cercanos. En sus inmediaciones se hallan las surgencias del arroyo de la Fuente del Rey, al 
Mapa 1: Situación de la provincia de Huelva en España (izquierda) y de la Sierra de Aracena al norte de la provincia de Huelva (derecha)

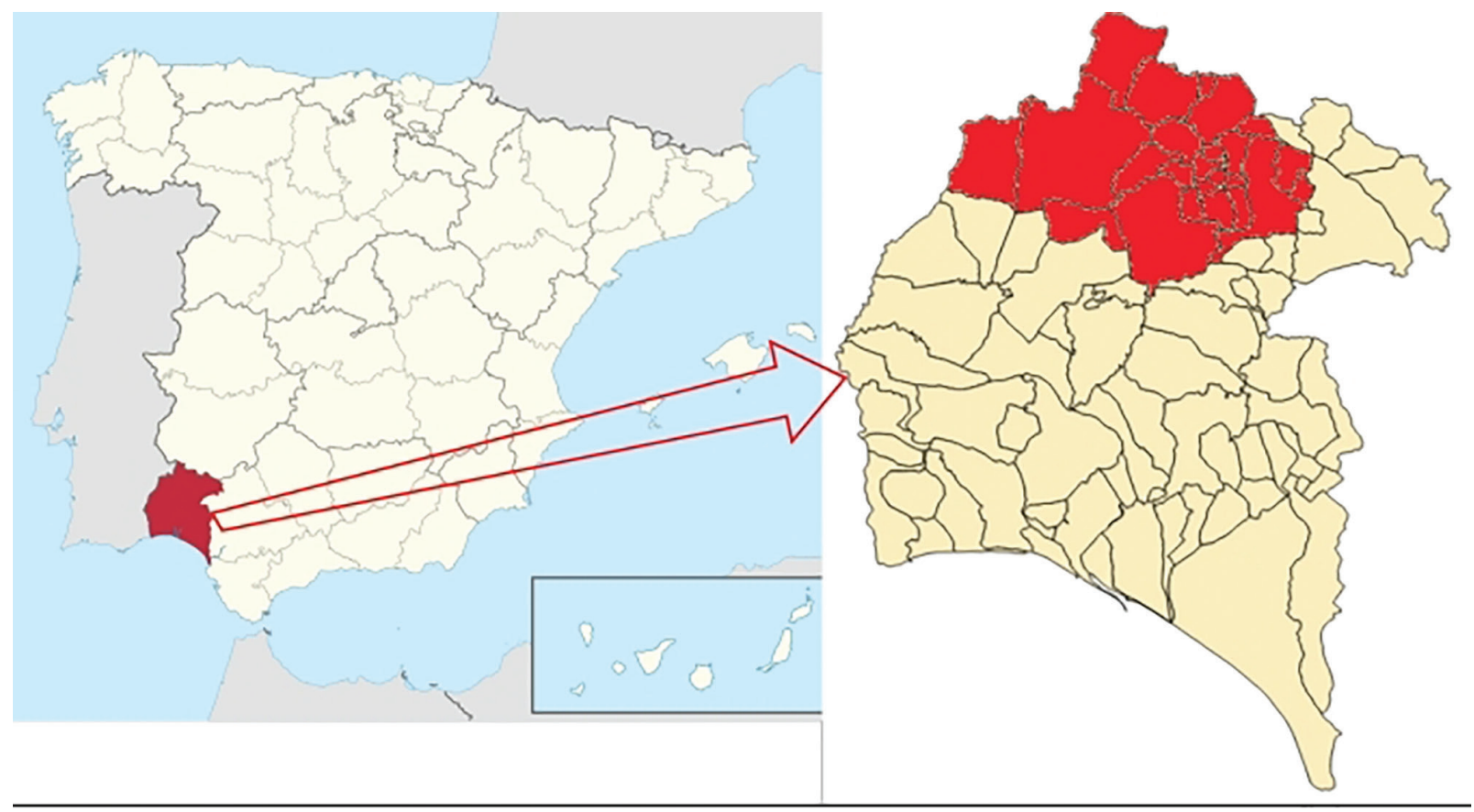

Fuente: elaboración propia.

noreste de Aracena, dentro de su término municipal, a unos $1,5 \mathrm{~km}$ del casco urbano, y en las proximidades del Molino Pombo, a una altitud de $620 \mathrm{~m}$. Constituyen el drenaje natural de la zona oriental de la Sierra de Aracena ${ }^{4}$. Al norte de este arroyo, a unos $2 \mathrm{~km}$ de su nacimiento, se encuentra un lugar con el topónimo de Puerto de los Molinos.

En el informe testifical de 1497 (Tabla 1), el primer molino recogido es el de la mujer del escribano Pedro Martín; del que literalmente se dice que linda con la dicha Fuente del Rey. Además, tenemos la suerte de que, de la mayor parte de los restantes inmuebles del arroyo, se indica que colindaban con el anterior, comenzando por el antedicho. De modo que es bastante sencillo situarlos en un mapa, y su representación, con no poder ser del todo exacta, no distará mucho del lugar donde se ubicaron hace más de 500 años. Sin que sea posible determinar sobre qué margen del curso estaban originalmente.

En el tercer inmueble de la citada relación encontramos muchas de las claves del sistema de propiedad y tributación de estas instalaciones hidráulicas. Se trata del herido - un herido de molino era el desvío de un curso de agua para mover la maquinaria de un molino hidráulico; también podía ser la cantidad de agua precisa para hacerlo funcionar-de Hernando Francisco, el viejo; que, como ya he dicho, estaba

\footnotetext{
4. http://www.conocetusfuentes.com/ficha_detalle.php?id_fuente=53.
}

contiguo al anterior, y a otros dos molinos suyos en construcción, que nunca habían molido. Se encontraban en sus tierras, y no tenían vegas -cuérnago o regato para desviar el agua al molino - ni isletas - trozo de tierra aislado entre el cauce natural y la vega que llevaba el agua al molino, y que luego, una vez aprovechada para mover sus ruedas y/o regar las huertas adyacentes, era devuelta al curso fluvial-de realengo; esto es, la vega y la isleta que formaba estaban en tierras del propietario del molino, no públicas. Por ello, nunca pagaron diezmo ni otro tributo. Se mostró una carta de merced del dueño en la que, a su yerno, Juan García de Terrazas, le había dado licencia la ciudad para hacer dichos ingenios, a cambio de entregar anualmente al almojarifazgo $80 \mathrm{mrs}$. por cada uno, y a condición de no venderlos sin autorización conceji ${ }^{5}$. Al menos otros tres artefactos eran de los que pudieron ser hermanos, Diego y Juan Martínez de la Corte. Como se aprecia en el Mapa 2, cercana a este arroyo de la Fuente del Rey está la aldea de Corteconcepción; de manera que este segundo apellido tal vez haga referencia a su localidad de origen.

Como se recoge en el Mapa 2, en el antedicho arroyo de la Fuente del Rey, en ese tramo de algo más de $4 \mathrm{~km}$, se encuentran unos 35 ingenios hidráulicos, en-

\footnotetext{
5. Fernán Francisco y Juan García de las Terrazas consiguieron en 1497 otras tres licencias para molinos en Arroyo de los Molinos, lo que demostraría que este último curso de agua era la continuación del arroyo de la Fuente del Rey (González Arce, 2020b). Las siguientes referencias a licencias edilicias de molinos han sido tomadas del anterior trabajo.
} 
Tabla 1: Relación de inmuebles hidráulicos de Aracena I (1491 y 1497) y su tipología: molinos harineros (M), molinos batanes (B) y azudes o heridos $(\mathrm{H})$

\section{Molinos de la rivera de la Fuente del Rey}

Molino de la mujer del escribano Pedro Martín, linda con dicha Fuente del Rey

Herido de molino de Elvira, hija de Cristóbal García

Herido de Hernando Francisco, el viejo, linda con el anterior y con otros 2 molinos suyos en construcción, que nunca han molido

Molino de la mujer de Juan Domínguez, Catalina Pérez, linda con los anteriores

Molino de Juan de Castilla, escribano, linda con el anterior

Molino de Inés Martínez, mujer de Hernando Francisco, difunto, con un herido que se llamaba de Las Tablas

Molino de Toribio Martínez y sus compañeros, le dicen el Molino Nuevo, linda con el anterior

Molino de Juan de Escobar y hermanos, le dicen el Molino Blanco, linda con el anterior

Molino de Toribio de Escobar, linda con el anterior

Molino de Juan Cristóbal y su compañero, le dicen del Cerrado, linda con el anterior

Herido del mismo propietario y linda con el anterior

Herido de Francisco Pérez, linda con el anterior

Heridos del mismo dueño, que llaman de Los Ayelones, lindan con el anterior

Molino de Juan Martínez y Juan Esteban, el Abad, le dicen del Naranjo, linda con el anterior

Molino de Inés Martínez, mujer de Hernando Francisco, le dicen de Las Encinillas, linda con el anterior

Molino de Juan Martínez de la Fuente de Cantos, le dicen de Juan Pérez, linda con el anterior

Molino de Diego Martínez de la Corte, le dicen de La Pasada, linda con el anterior

Molino de la mujer de Juan Domínguez, Catalina Pérez, y Álvaro Hernández, le dicen de Fontes, linda con anterior

Herido de Catalina Pérez, mujer de Juan Domínguez, linda con el anterior, en herido del batán

Molino de Juan Alonso de la Bolsa y sus compañeros, le dicen de Los Araceneros, linda con el anterior

Molino de Lorenzo Sánchez, linda con el anterior

Molino de Juan Martínez de la Corte, linda con el de Lorenzo Sánchez del Puerto

Otro molino del anterior, que linda con el de arriba

Otro molino del anterior, linda con el de la mujer de Luis Hernández, en la misma rivera

Molino de Francisco Pérez, se le dice del Reventón, linda con el molino de Juan Martínez de la Corte

Molino de Inés Martínez, mujer del citado Hernando Francisco, difunto, se le dice el del Medio, linda con el anterior

Molino de Catalina González, mujer de Lorenzo Hernández, difunto, se le dice del Reventón, linda con el anterior

Molino de Alonso Sánchez de la Sierra y sus compañeros, se le dice de la Torre, linda con el anterior

Molino del dicho Alonso Sánchez de la Sierra y su compañero Pedro Páez, se le dice de Pedro Páez, linda con el anterior

Molino de Alonso Sánchez de la Sierra, se le dice Chico, linda con el anterior

Molino y batán de la mujer de Luis Hernández Palero, difunto que linda con el anterior

Molino de Hernando Francisco, el viejo, linda con el molino de Juan Martínez de la Corte

Molino de Hernando Domínguez y sus compañeros, le dicen de la Coja, linda con el anterior

Fuente: AMS, Diversos, 603 y 719 


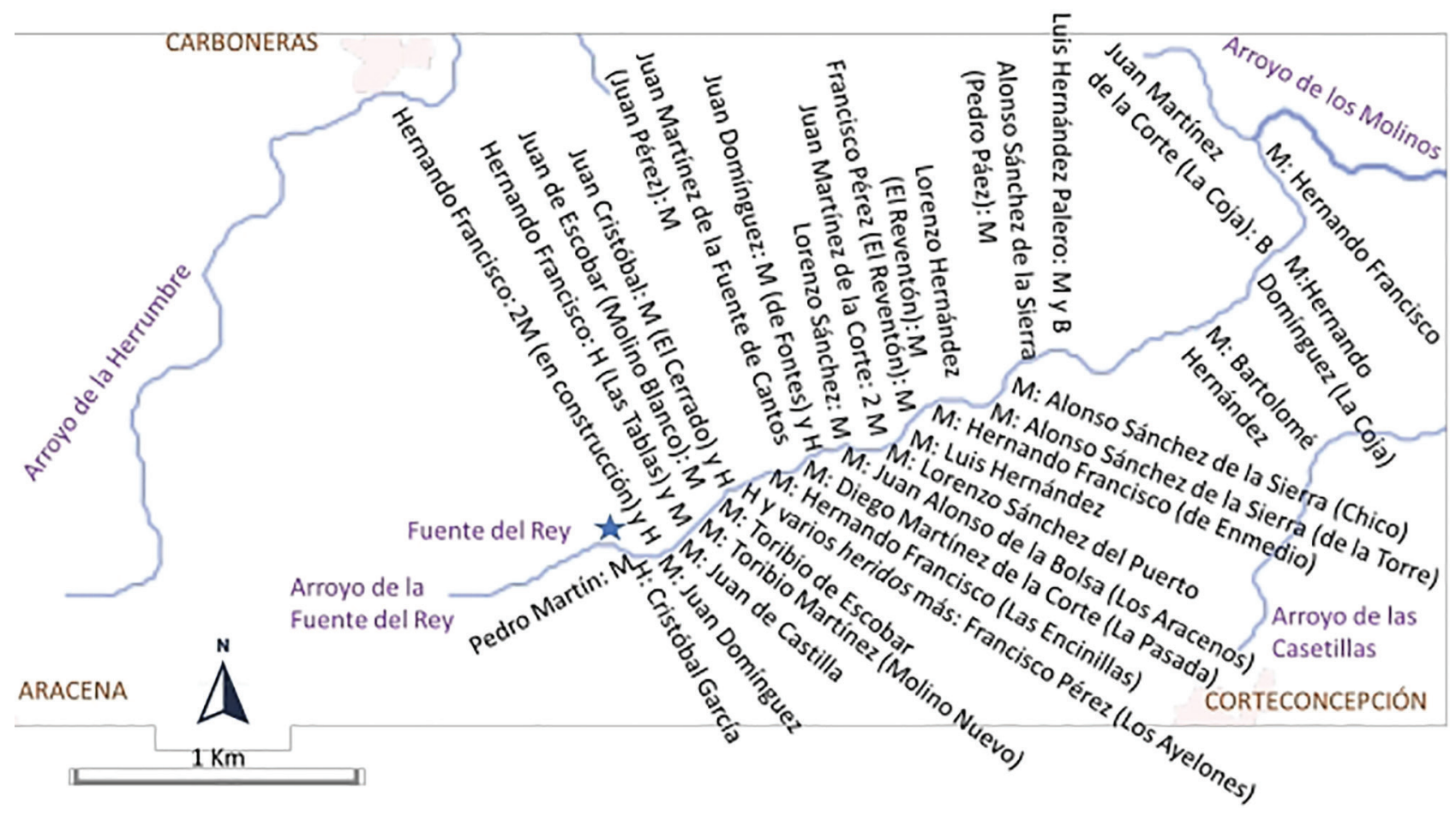

Fuente: AMS, Diversos, 603 y 719

tre molinos y azudes, lo que se explica porque, entre el nacimiento en la propia Fuente del Rey, sita a los antedichos $620 \mathrm{~m}$ de altitud, y su confluencia con el arroyo de los Molinos, a unos $400 \mathrm{~m}$, hay más de 200 metros de desnivel, lo que supone una pendiente media del 13,3\%.

\section{Arroyo de los Molinos}

El susodicho arroyo de la Fuente del Rey, en el tramo final de su desembocadura en la rivera de Huelva, en lo que hoy es el embalse de Aracena, recibe el nombre de barranco de los Molinos (o de los Molinillos), de manera que, y a falta de otros cauces de agua con este nombre, hemos de identificarlo como el antiguo Arroyo de los Molinos -no obstante, en el cercano arroyo de Carboneras, o de la Herrumbre (Mapa 2), en su confluencia, igualmente con el Huelva, hay un camino conocido como Arroyomolinos- ${ }^{6}$. En él se localizaría una aldea arace-

\footnotetext{
6. Sin embargo, Pérez-Embid Wamba (1996, 51-52), interpretó que la aldea de Arroyo de los Molinos, que según él concentraba la mayor parte del equipamiento molinar, que veremos se encontraba más bien en el arroyo de la Fuente del Rey, coincidía con la rivera de la Fuente del Castaño. Aunque, como comprobaremos más abajo, este otro curso de agua contó con sus propios artefactos, que no se pueden identificar con los del Arroyo de los Molinos de la pesquisa de 1491. Buena parte de los topónimos, parajes, lugares y aldeas a los que me voy a referir, como Arroyo de los Molinos, El Castaño o Las Carboneras, eran antiguos núcleos pertenecientes al concejo de Aracena, que registró, debido a sus características topográficas y pluviométricas, una gran dispersión de su población (Pérez-Embid Wamba, 1998, pp. 130-131).
}

nense conocida como Arroyo de los Molinos, que habría tomado su nombre, o se lo habría proporcionado, a esta rivera del Arroyo de los Molinos. Hoy, al inicio del mismo hay un tal Cortijo de los Molinos, y hacia la mitad otro llamado Cortijo Cerca de los Molinillos. Allí se radicaron unos 10 ingenios (Mapa 3), en un curso fluvial de una longitud similar al arroyo de la Fuente del Rey, unos $4 \mathrm{~km}$, pero que apenas contó con un tercio de sus artefactos, porque su pendiente es asimismo significativamente menor; pues en su trayecto se pasa de una altitud de unos 400 $\mathrm{m}$, que era la que había al final del arroyo de la Fuente del Rey, a unos 350, en su desembocadura en el Huelva. Lo que da lugar a un desnivel medio de algo más del 1\%.

Hay que hacer notar que el primer propietario del listado de 1491 en este arroyo se llamó, precisamente, Juan Domínguez de los Molinos ${ }^{7}$, que sería el mismo que el del Mapa 2; apellido claramente vinculado al topónimo de la aldea donde tenía sus instalaciones molinares -también reaparece Juan Martínez de la Corte ${ }^{8}$,

\footnotetext{
7. Al mismo le fue dada en 1489 una licencia para un batán en este Arroyo de los Molinos, entre el molino de La Pasada y el batán de Fernán García; que no sabemos si eran algunos de los artefactos recogidos en el Mapa 3, aunque hay uno de La Pasada en la 1. Estuvo casado con Catalina Pérez, apodada la Camacha, a la que se le concedió permiso en 1503 para transformar este antiguo batán en molino de pan. Por otra parte, asimismo en el Mapa 3 se aprecia cómo dos de las instalaciones pertenecían a Luis Fernández Arreciado, quien obtuvo su autorización para su batán de paños, frisas y sayales en 1478 .

8. En 1493 Juan Martínez obtenía una licencia para un molino de pan de dos asientos en esta rivera de Arroyo de los Molinos.
} 
Mapa 3: Instalaciones de Arroyo de los Molinos, en término de Aracena (1491-1497)

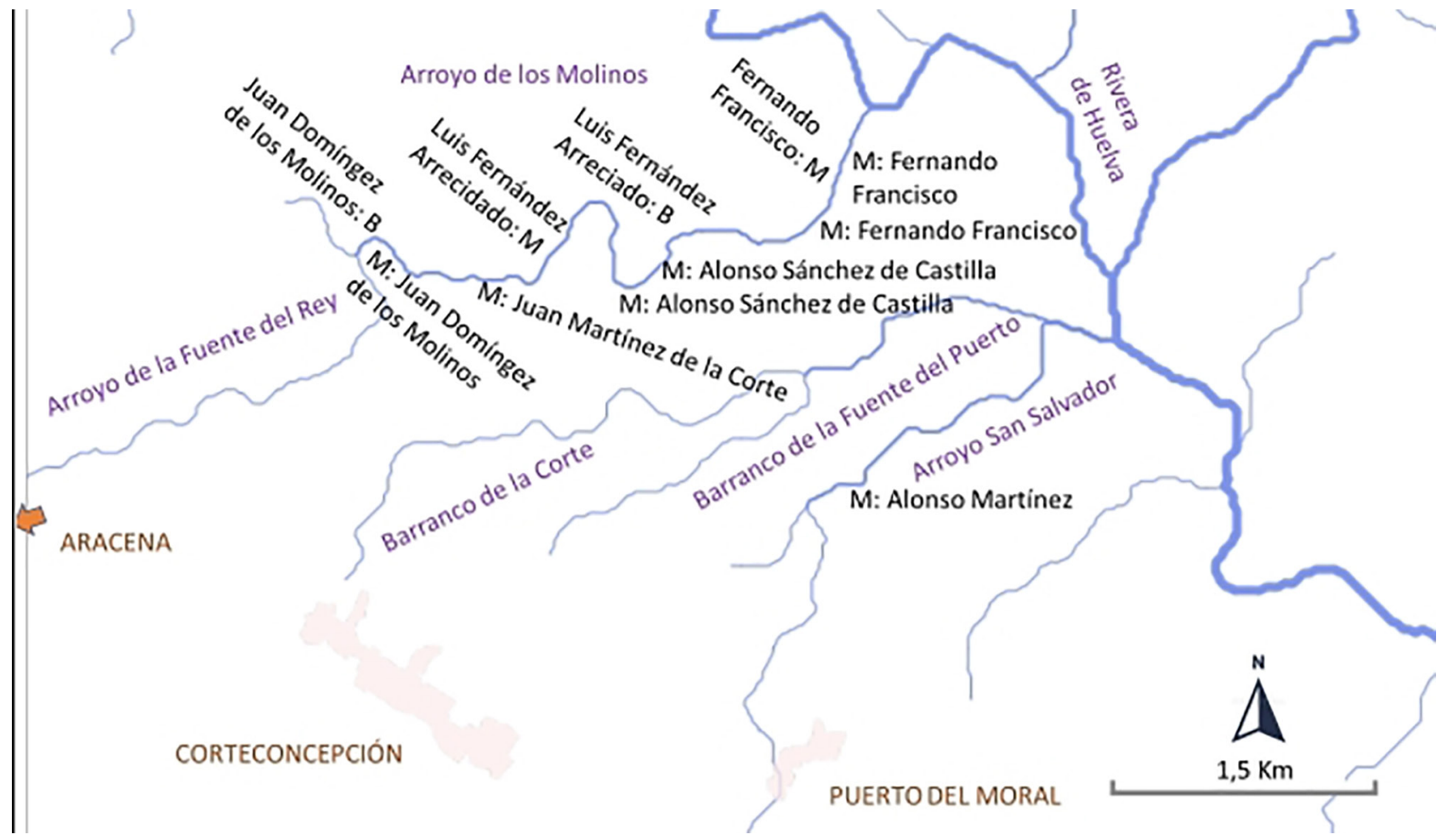

Fuente: AMS, Diversos, 603 y 719

que lo habría estado a Corteconcepción, como vimos-. No sabemos en qué tramo se encontraban las mismas, por las que las he ubicado al principio del arroyo, junto al de la Fuente del Rey; y, las restantes a continuación, según aparecen en la antedicha pesquisa (Tabla 2). El último ingenio de la relación es uno de los tres que, al parecer, tuvo Fernando Francisco. El primero, según su mujer, Inés Martínez, lo había construido su suegro, tenía más de 50 años y estaba en este curso de agua. El segundo lo había comprado el propio Fernando Francisco, tenía unos 25 años y se encontraba, igualmente, en dicho arroyo. Si bien, del tercero, que pertenecía al susodicho y a su madre, con unos 55 años, no se dice dónde se ubicó; aunque yo lo he situado junto a los anteriores, igualmente en el arroyo de los Molinos.

\section{Rivera del Castaño}

En el actual municipio de Los Marines, cercano a Aracena (villa a la que perteneció esta aldea en la Edad Media), al oeste de la localidad, se encuentra una fuente conocida como la del Castaño, junto a un barranco, asimismo, de igual nombre. Este barranco, tras bordear un altozano llamado Los Molinos, se une unos kilómetros más abajo de su curso, y hacia el norte, entre otros, al llamado arroyo de
Tabla 2: Relación de inmuebles hidráulicos de Aracena II (1491 y 1497) y su tipología: molinos harineros (M), molinos batanes (B) y azudes o heridos (H)

\begin{tabular}{lc}
\hline \multicolumn{1}{c}{ Inmueble } & Tipo \\
\hline Molinos del arroyo Molinos de pan de Juan Domínguez de los Molinos & $\mathrm{M}$ \\
Molino batán de paños y frisas, de Juan Domínguez de los Molinos & $\mathrm{B}$ \\
Molino de pan de Juan Martínez de la Corte, vecino del lugar & $\mathrm{M}$ \\
Molino de Luis Fernández Arreciado & $\mathrm{M}$ \\
$\begin{array}{l}\text { Molino de pan de Alonso Sánchez de Castilla, se llama de Andrés } \\
\text { Pérez }\end{array}$ & $\mathrm{M}$ \\
Molino de pan del anterior, Alonso Sánchez de Castilla & $\mathrm{M}$ \\
Molino batán de paños, frisas y sayales de Luis Fernández Arreciado & $\mathrm{B}$ \\
Molino de Inés Martínez, mujer de Fernando Francisco & $\mathrm{M}$ \\
Molino de Fernando Francisco (Aracena) & $\mathrm{M}$ \\
$\begin{array}{l}\text { El anterior, Fernando Francisco, en nombre su madre, dijo que tanto } \\
\text { ella como su padre habían comprado un molino }\end{array}$ & $\mathrm{M}$ \\
\hline
\end{tabular}

Fuente: AMS, Diversos, 603 y 719 
Castañuelo, con el que confluye por su margen derecha; mientras que un poco más abajo lo hace, por la izquierda, con el arroyo de la Fuente del Castaño. En adelante, estos tres valles dan lugar al arroyo de la Fuente del Castaño, propiamente dicho, que en el siglo XV se denominó rivera del Castaño. Tras esta triple confluencia, a unos cientos de metros más hacia el norte se encuentra el pueblo de Castañuelos (o Castañuelo), perteneciente al municipio aracenense, de cuyo núcleo urbano dista $7 \mathrm{~km}$. Allí se radican varias fuentes más que nutren el citado curso de agua. Una llamada manantial de Fuente Castaño, a unos 300 m del casco urbano, y a $480 \mathrm{~m}$ de altitud ${ }^{9}$. Las otras fuentes del lugar son de más escaso caudal: la del Barranco ${ }^{10}$, en el propio casco urbano junto al barranco de Castañuelo; a unos metros de la fuente de las Pilas ${ }^{11}$, que se encuentra en tal barranco; y la de los Llanos ${ }^{12}$.

Como es fácil deducir, el caudal del arroyo de la Fuente del Castaño aumenta sensiblemente tras su paso por Castañuelos, por lo que es de suponer que los inmuebles hidráulicos sitos en el siglo XV en la rivera del Castaño se radicasen, sobre todo, a partir de dicho punto, hasta su desembocadura en la rivera de Huelva. Así lo corrobora, al menos, el primero de ellos que aparece en la relación de 1497 (Tabla 3), el molino de la mujer de Antón Pravos, del que se dice que estaba en el Huelva; esto es, por tanto, en la confluencia de ambas riveras, la de la Fuente del Castaño y la de Huelva. Sin embargo, los dos siguientes apuntes de la susodicha pesquisa de 1497 corresponden a dos heridos sitos en Las Carboneras, muy probablemente en referencia al arroyo de tal nombre, por lo que los veremos más abajo. Tras ellos se recogen varios inmuebles, lindantes entre sí: el molino de Gonzalo Hernández Pericón, el de éste y su mujer Inés Alonso, nieta de Antón Alonso, que lo había edificado, y dos heridos, otro de Gonzalo Hernández y uno de los herederos del difunto Alonso Vicente; de los que no se indica su situación exacta, por lo que los he colocado (Mapa 4) hacia el sur de Castañuelos; pues, de los otros restantes, asimismo colindantes entre ellos, sí se dice que estaban, como el primero, próximos al Huelva, en la desembocadura del arroyo, por tanto. Entre ellos el molino de pan de la mujer de Vicente Yáñez, difunto ${ }^{13}$. Aparte de ambos conjuntos de ingenios, se encuentran otros va-

\footnotetext{
9. http://www.conocetusfuentes.com/ficha_detalle.php?id_fuente=51.

10. http://www.conocetusfuentes.com/ficha_detalle.php?id_fuente=4720

11. http://www.conocetusfuentes.com/ficha_detalle.php?id_fuente $=4718$.

12. http://www.conocetusfuentes.com/ficha_detalle.php?id_fuente=4719.

13. Llamada Isabel Alfonso, con licencia de 1474 por la que sabemos que el segundo apellido del marido era Renge. En el Mapa 4 hay dos instalaciones a nombre de Pedro Sánchez, el último Cristóbal de segundo apellido; como de ambos se dice que eran difuntos, puede que fuese el mismo propietario
}

rios, como el del difunto Alonso Vicente, de los que no se indica que estuviesen próximos a ningún otro, por lo que los he situado hacia la cabecera del arroyo, únicamente por cuestiones de espacio, pues no es posible saber su ubicación aproximada o si estaban cerca unos de otros.

En esta ocasión hablamos de algo menos de 30 edificios de molinos, 30 con los dos del arroyo Carboneras, en un curso de agua del que no sabemos su longitud exacta, pero que, como se aprecia en el Mapa 4, sería de casi el triple que el visto del arroyo de la Fuente de Rey, si contamos desde la fuente del Castaño, en el barranco del Castaño, a algo menos de $700 \mathrm{~m}$ de altitud, hasta la desembocadura de esa rivera del Castaño (hoy arroyo de la Fuente del Castaño) en la rivera de Huelva, a unos $350 \mathrm{~m}$.

Como he adelantado, en la pesquisa de 1497, en el apartado dedicado a los inmuebles de la rivera del Castaño, los heridos de Juan Gómez y de Juan Hernández se radicaban en el arroyo de Las Carboneras. En el momento de la encuesta estaban en desuso, de forma que, del segundo, que contaba con una antigüedad de 30 años, se llega a decir que hacía 10 que no molía ni tenía agua. Este valle, hoy arroyo Carboneras, que desemboca en la rivera de Huelva -donde vimos había un camino llamado Arroyomolinos-, es el resultado de una triple confluencia en el pueblo al que da nombre, Carboneras, sito al norte de Aracena, en su municipio: de un lado el cauce que recoge el agua de la fuente de los Romeros; de otro, el arroyo de la Herrumbre ${ }^{14}$; y, por último, el arroyo de la Casa Blanca.

\section{Arroyo de Valdelarco y otros}

Este curso fluvial discurre entre la localidad de igual nombre y la de Cortelazor, para morir, como todos los anteriores, en la rivera de Huelva. El tercer apartado, relativo a las instalaciones hidráulicas, de la pesquisa de 1497 de Aracena, se titula Robledo y Valdelarco (Tabla 4). Probablemente, el primero sea Castaño del Robledo, un municipio situado al sur del pueblo de Valdelarco, entre Jabugo y Valdeheridos -curioso topónimo que, muy posiblemente, haga referencia a los heridos de molino que estamos viendo-, al oeste del antedicho lugar de Los Marines -también cerca de este pueblo y del

de las dos. En 1478 dicho Pedro Sánchez Cristóbal obtuvo un permiso para erigir un molino de pan en su huerta de la fuente del Castaño. Asimismo, tenemos la licencia de uno de los molinos de Francisco de Esquivel, de 1496. Archivo Municipal de Sevilla (en adelante AMS), Libro de Mayordomazgo (LM) 1478-1479, nº 100 y 1496, nº 76.

14. La fuente Herrumbre está a $1 \mathrm{~km}$ al norte de Aracena, en la carretera de Carboneras (http://www.conocetusfuentes.com/ficha_detalle.php?id_ fuente=5458) 
Tabla 3: Relación de inmuebles hidráulicos de Aracena III (1491 y 1497) y su tipología: molinos harineros (M), molinos batanes (B) y azudes o heridos $(\mathrm{H})$

\begin{tabular}{|c|c|}
\hline Inmueble & Tipo \\
\hline \multicolumn{2}{|c|}{ Molinos de la rivera del Castaño (arroyo de la Fuente del Castaño) } \\
\hline Molino de la mujer de Antón Pravos, en Huelva (rivera de Huelva) & M \\
\hline Herido de Juan Gómez, en Las Carboneras & M \\
\hline Herido de Juan Hernández, en Las Carboneras & $\mathrm{H}$ \\
\hline Molino de Gonzalo Hernández Pericón & M \\
\hline Molino de Gonzalo Hernández e Inés Alonso, linda con el anterior & M \\
\hline Herido de Gonzalo Hernández, linda con el anterior & $\mathrm{H}$ \\
\hline Herido de Alonso Vicente, difunto, pertenece a sus herederos & $\mathrm{H}$ \\
\hline Molino de pan de la mujer de Vicente Yáñez, difunto, cerca del Huelva & M \\
\hline Molino de Alonso Guerra, linda con el anterior & M \\
\hline Herido, linda con el anterior, está por hacer & $\mathrm{H}$ \\
\hline Molino de Alonso Yáñez del Castaño, linda con el anterior & M \\
\hline Herido de Álvaro Alonso & $\mathrm{H}$ \\
\hline Molino de Alonso Pérez, linda con el anterior, en los Cabriles & M \\
\hline Molino de Luis Hernández Palero, linda con el anterior, & M \\
\hline Molino de Juan Maestre, linda con el anterior & M \\
\hline Molino de Alonso Guerra, linda con el anterior & M \\
\hline Molino de Lorenzo Garpaza, linda con el anterior, & M \\
\hline Molino de Juan Martínez de la Plaza, linda con el anterior & M \\
\hline Herido de Hernando Francisco, escudero de Hernando Domínguez, linda con el anterior & M \\
\hline Molino de la mujer de Hernando García, difunto, linda con el anterior & $\mathrm{H}$ \\
\hline Molino de Juan de Mesa, linda con el anterior & M \\
\hline Molino de la cofradía de S. Sebastián, linda con el anterior, con 40 años, en una huerta de dicha cofradía & M \\
\hline Molino de Beatriz Hernández, mujer de Diego Hernández, difunto, linda con el anterior & M \\
\hline Molino de Pedro Sánchez, difunto, linda con el anterior & M \\
\hline Molino de Francisco de Esquivel, linda con el anterior & M \\
\hline Molino del anterior junto al mismo & M \\
\hline Molino de la mujer de Luis Hernández Palero, difunto, junto a un batán & M \\
\hline Molino de pan de los hijos de Pedro Sánchez Cristóbal, difunto & M \\
\hline Molino de Alonso Martínez Guerra & M \\
\hline Molino de los herederos de Bartolomé Maestre & $\mathrm{M}$ \\
\hline
\end{tabular}

Fuente: AMS, Diversos, 603 y 719

barranco de la Fuente del Castaño, hay hoy día unas Casas del Robledo-y, por tanto, asimismo de Aracena. Ello porque, al sureste de dicho Castaño del Robledo, y al sur de Fuenteheridos - de nuevo un topónimo que alude a los heridos o azudes - se encuentra el municipio de Alájar ${ }^{15}$, y dado que, de uno de los molinos de esta

15. En Alájar hay un camino de los Molinos, donde está la fuente Nueva de dicho camino, que antes vertía sus aguas a la rivera de Alájar (http://www. conocetusfuentes.com/ficha_detalle.php?id_fuente=5793). Allí también se relación, el de Juan García de la Morilla, se dice que estaba situado en Alhajar. De otro, de Pedro González de Alhajar, se indica que lindaba con el Robledo, que sería Castaño del Robledo, por lo que estaría emplazado en la rivera de Jabugo - aunque al noroeste de Alájar hay un paraje llamado Casa del Robledo, cerca del barranco de

halla la fuente La Gaja (http://www.conocetusfuentes.com/ficha_detalle. php?id_fuente=5792). 
Mapa 4: Instalaciones de la rivera del Castaño y otras, en término de Aracena (1491-1497)

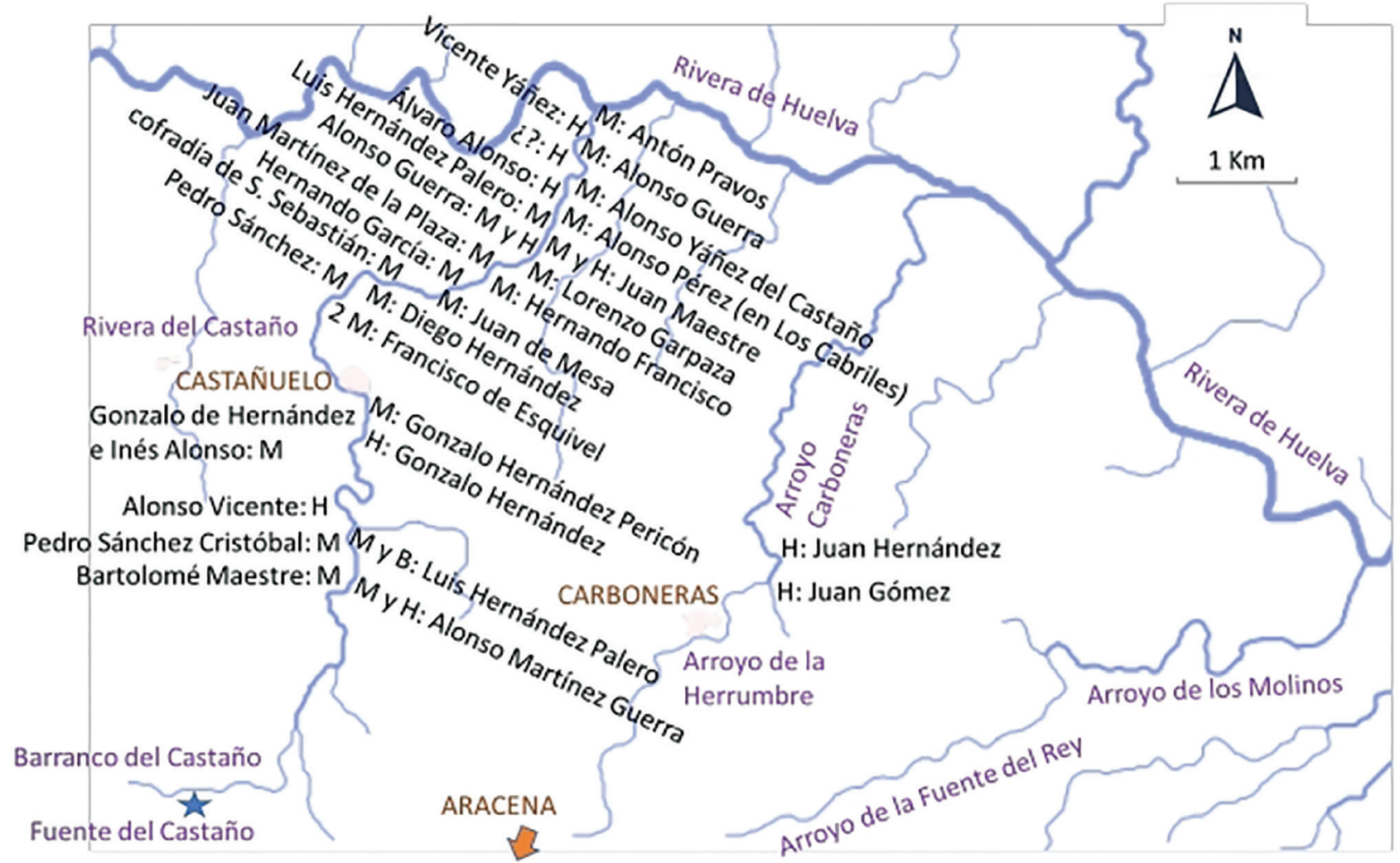

Fuente: AMS, Diversos, 603 y 719

Tabla 4: Relación de inmuebles hidráulicos de Aracena IV (1491 y 1497) y su tipología: molinos harineros (M), molinos batanes $(B)$ y azudes o heridos $(H)$

\begin{tabular}{ll}
\hline \multicolumn{1}{c}{ Inmueble } & Tipo \\
\hline \multicolumn{1}{c}{ Molinos del Robledo y Val del Arco } & \\
\hline Molino de Alonso Vázquez en Val del Arco & M \\
Molino de Juan García de la Morilla, en Alhajar & M \\
Molino llamado de la Navarra de Linares & M \\
Molino de Diego López, linda con el anterior & M \\
Molino de Pedro González de Alhajar, linda con el Robledo & M \\
Herido de Martín Hernández, calero, que fue molino, en Orullos & H \\
Molino de Alonso del Alcázar, linda con el anterior & M \\
Molino de Luis Martínez Bejarano, en Orullos & M \\
Herido de Alonso Guerra, que fue molino, en La Molinilla & H \\
\hline
\end{tabular}

Fuente: AMS, Diversos, 603 y 719

Valle Peral, que muere en la rivera de Alájar-. Además, al sur de Alájar hay varios topónimos relacionados con Orullos (Montes de Orullos, Llano de Orullos, Casas de Orullos...), mientras que otro de los heridos de la pesquisa, el de Martín Hernández, se hallaba en Orullos, que en el siglo XV era una aldea de Aracena, de la que hoy solamente se conserva su ermita, sita en la confluencia de las riveras de Alájar y Linares ${ }^{16}$. Un topónimo más de este listado es el de La Molinilla, donde estaba un último herido antiguo en desuso, el de Alonso Guerra. En Linares de la Sierra, municipio al este de Alájar y al sur de Los Marines, hay una rivera denominada de Las Molinillas (o de Los Molinillos), que, tras confluir con el barranco del Valle de la Palma, da paso al arroyo de Vallesilos, también conocido como rivera de Linares, antes citada. En ella se localizaría el tercer molino de esta relación, llamado de la Navarra de Linares.

De este modo, los nueve ingenios de Valdelarco y Robledo (Castaño del Robledo) se ubicarían en una serie de cursos de agua del noroeste y oeste de Aracena, en los arroyos de Valdelarco, rivera de Jabugo (a su paso por Castaño del Robledo), rivera de Alájar y riveras de Linares y Las Molinillas -así como en el barranco de la Urraleda, como luego veremos-. El primero de ellos, como he dicho, desemboca en la rivera de Huelva; el segundo, en el río Múrtiga o Múrtigas, que nace en la fuente de los Doce Caños ${ }^{17}$, en el centro urbano de Fuenteheridos; y los restantes, son tributarios del río Odiel.

\footnotetext{
16. Sobre Orullos en el siglo XV, Pérez-Embid Wamba, 1998, 130.

17. http://www.conocetusfuentes.com/ficha_detalle.php?id_fuente=70.
} 
En el Mapa 5 no se han situado las instalaciones hidráulicas en el lugar aproximado en el que debieron estar, por falta de información al respecto, sino solamente en el curso de agua en el que, al parecer, se debieron radicar. Eso sí, cuando se indica en la fuente documental que eran colindantes, se han colocado juntas.

\section{Río Odiel}

Se trata del conjunto de instalaciones hidráulicas más difíciles de localizar, por la falta de referencias concretas, o porque las que aportan las fuentes son vagas o no se corresponden con topónimos actuales. Comienza la relación de 1497 con el molino de Juan Blázquez, en Valdealmonaster (Tabla 5). Se trató de una antigua aladea aracenense integrada en el concejo de Alájar por Carlos II, cuando a esta última la segregó de Aracena. No he podido localizar su ubicación exacta, pero, al estar en este grupo de ingenios del río Odiel, debió de encontrarse al oeste de Orullos, que también se unió al nuevo municipio de Alájar, y al suroeste de Almonaster la Real ${ }^{18}$. Es posible que Valdealmonaster se hallase sobre la actual rivera de Almonaster, por lo que situaré allí dicho molino, así como el otro al él lindante. El tercer edificio es de Gómez de Llana, contiguo al de la mujer de Alonso Martínez de Llana. Puede que este último apellido fuese un topónimo que haga referencia a Llanos de la Aliseda, sito entre la rivera Escalada y el barranco del Pino, que van a morir al río Odiel, si bien el último lo hace previamente en la rivera Seca. Se trata solamente de una posibilidad, apoyada en que el quinto artefacto es el molino de Sebastián Alonso, levantado en la rivera del Ejido. Curso de agua que tampoco he localizado. Sin embargo, al norte de Llanos de la Aliseda, a pocos metros se encuentran las cumbres de El Ejido. Por ello colocaré estas máquinas, y otras a ellos linderas, en la antedicha rivera Seca. El último de la relación, el molino de Alonso Martínez de Llana (nuevamente la Llana) se dice que estaba en el Odiel, algo demasiado impreciso, por tratarse de un curso fluvial tan extenso e importante, por ello lo voy a poner entre la desembocadura en el mismo de la susodicha rivera Seca y la de la también mencionada Escalada.

En el Mapa 6 no se han situado las instalaciones hidráulicas en el lugar aproximado en el que debieron estar, por falta de información al respecto, sino solamen-

\footnotetext{
18. Si bien Pérez-Embid Wamba, (1996, 52-53), se interroga si se trataría de la actual Santa Ana la Real.
}

te en el curso de agua en el que, al parecer, se debieron radicar.

\section{Otras instalaciones}

Tras la relación de inmuebles del Odiel, aparecen algunos en lugares diversos, que he ido emplazando junto con los anteriores, en caso de que se localizasen en los mismos cursos de agua (Tabla 6). Como el molino de Juan Martínez de la Corte, lindante con el de Lorenzo Sánchez del Puerto, en el arroyo de La Fuente del Rey, y los otros de dicho Juan Martínez, dos contiguos al primero (Mapa 2) ${ }^{19}$. Igual proceder he seguido con el molino de Luis Martínez Bejarano, que al estar situado en Orullos lo he puesto con los de esa aldea (Mapa 5). El de Fernando González Martínez, al ser el único del arroyo de La Fuente del Concejo ${ }^{20}$ (hoy río Banegas), lo he recogido en el Mapa 4. Mismo caso del de Alonso Martínez, sito en la aldea del Puerto del Moral (hoy municipio al este de Aracena); posiblemente, en el arroyo San Salvador, que va a morir a la rivera de Huelva, o en el barranco de la Fuente del Puerto (Mapa 3).

En la pesquisa de 1491 se incluye un último molino, de Juan Alonso del Chaparral ${ }^{21}$, que queda localizado en el arroyo de la Furraleda (o Hurraleda), que, como veremos (Mapa 7), se encontraba en Galaroza.

\section{Galaroza}

Núcleo que perteneció a Aracena, al noroeste de la villa, entre Castaño del Robledo y Valdelarco (Mapa 4 y Mapa 6); fundado en torno a la actualmente denominada fuente de Nuestra Señora del Carmen, que se halla junto a la iglesia ${ }^{22}$. Las aguas abundantes de este surgimiento iban a morir al río Múrtiga, que discurre cercano, en el actual paraje de Los Molinos.

Precisamente, según la pesquisa de 1497 (Tabla 7 y Mapa 7), exclusiva para esta aldea como vimos, en lo que allí se llama rivera de Galaroza, de la que se dice nacía cabo las casas de dicho lugar - esto es, sería el curso de agua que surgía en la fuente urbana y llegaba hasta el Múrtiga-, se situaba el primer artefacto

\footnotetext{
19. Lorenzo Sánchez del Puerto obtuvo licencia en 1492 para un molino harinero en Arroyo de los Molinos. Como el resto de sus ingenios estaban en la fuente del Rey, se refuerza la idea de que el primero era el curso final del segundo.

20. En el casco urbano aracenense, cuyas aguas proceden de la vecina Gruta de las Maravillas (http://www.conocetusfuentes.com/ficha_detalle. php?id_fuente=52).

21. Con licencia para un Molino en Aracena en 1480 .

22. http://www.conocetusfuentes.com/ficha_detalle.php?id_fuente=71.
} 
Mapa 5: Instalaciones del arroyo de Val del Arco y otros, en término de Aracena (1491-1497)

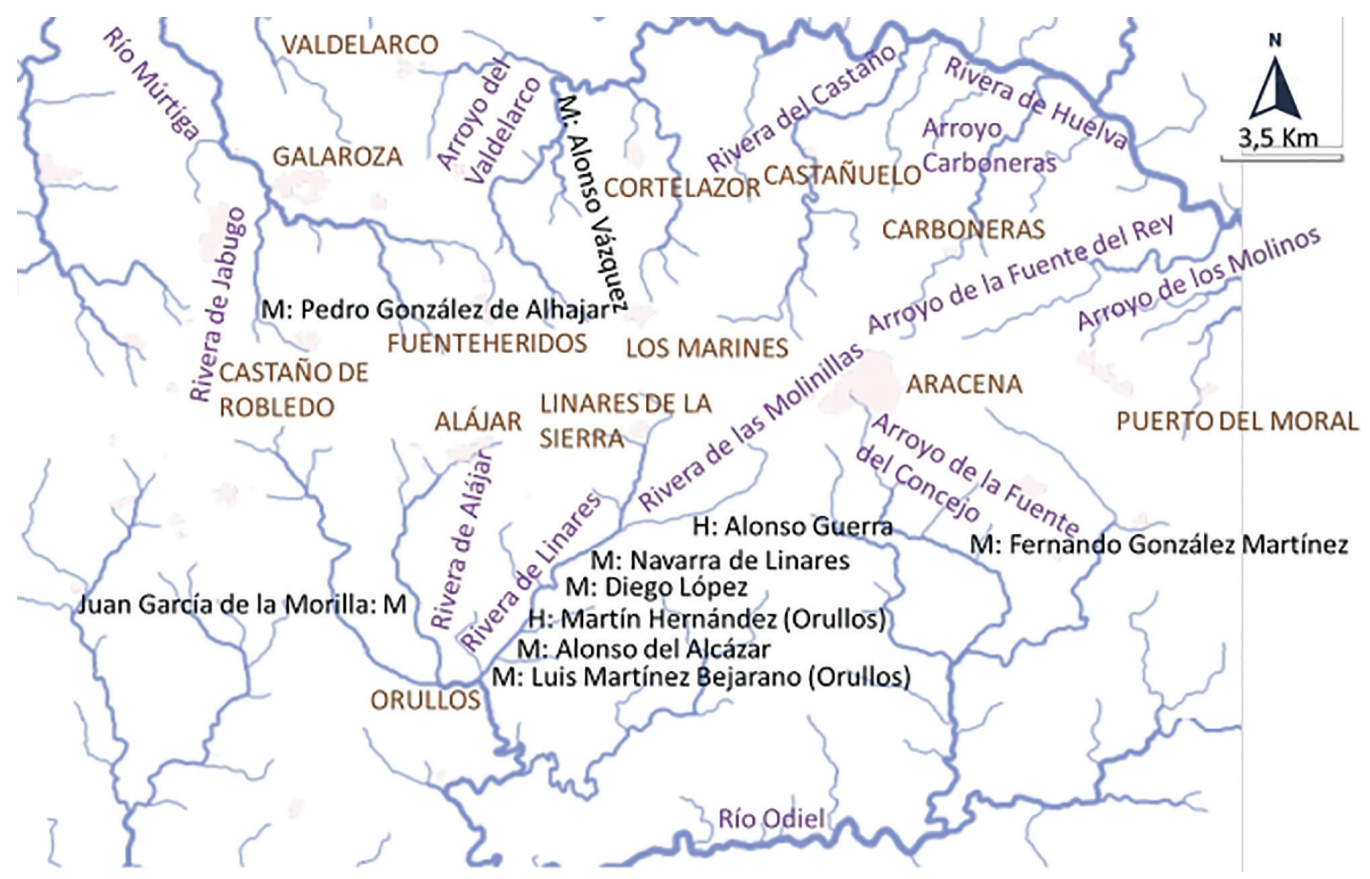

Fuente: AMS, Diversos, 603 y 719

Tabla 5: Relación de inmuebles hidráulicos de Aracena V (1491 y 1497) y su tipología: molinos harineros (M), molinos batanes (B) y azudes o heridos $(\mathrm{H})$

\begin{tabular}{lc}
\hline \multicolumn{1}{c}{ Inmueble } & Tipo \\
\hline \multicolumn{1}{c}{ Molinos del Odiel } & \\
\hline $\begin{array}{l}\text { Molino de Juan Blázquez, en donde dicen Valdealmonaster } \\
\text { Molino de Bartolomé Martínez, linda con el anterior }\end{array}$ & $\mathrm{M}$ \\
$\begin{array}{l}\text { Molino de Juan Esteban, clérigo de Aracena, que linda con el de la } \\
\text { mujer de Alonso Martínez de Llana }\end{array}$ & $\mathrm{M}$ \\
$\begin{array}{l}\text { Herido del hijo y yerno de Bartolomé Martínez de Jabugo, linda } \\
\text { con el anterior }\end{array}$ & $\mathrm{M}$ \\
$\begin{array}{l}\text { Molino de Sebastián Alonso en la rivera del Ejido } \\
\text { Molino de Diego Martínez, el Abad, linda con el anterior }\end{array}$ & $\mathrm{M}$ \\
$\begin{array}{l}\text { Herido de Juan González Muñiz, linda con el de Sebastián Alonso } \\
\text { y con el de arriba }\end{array}$ & $\mathrm{M}$ \\
$\begin{array}{l}\text { Molino de Alonso Martínez de Llana, en el Odiel } \\
\text { Fuente:AMS Diversos, }\end{array}$ & $\mathrm{M}$ \\
\hline
\end{tabular}

Fuente: AMS, Diversos, 603 y 719

Tabla 6: Relación de inmuebles hidráulicos de Aracena VI (1491 y 1497) y su tipología: molinos harineros (M), molinos batanes (B) y azudes o heridos $(\mathrm{H})$

\begin{tabular}{lc}
\hline \multicolumn{1}{c}{ Inmueble } & Tipo \\
\hline \multicolumn{1}{c}{ Otros Molinos } & \\
\hline Molino de Fernando González Martínez, en la Fuente del Concejo & $\mathrm{M}$ \\
Molino de Alonso Martínez, en la aldea del Puerto del Moral & $\mathrm{M}$ \\
Molino de pan de Juan Alonso del Chaparral, en el arroyo de la & $\mathrm{M}$ \\
\hline Furraleda (o Hurraleda) &
\end{tabular}

Mapa 6: Instalaciones del río Odiel y otros, en término de Aracena (1491-1497)

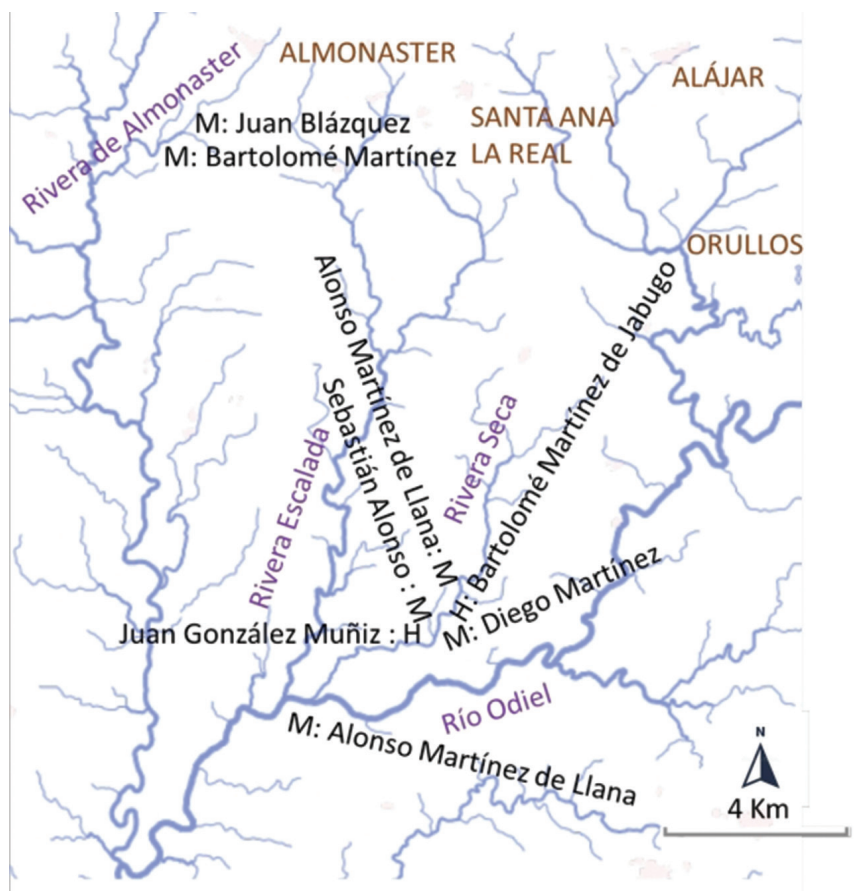

Fuente: AMS, Diversos, 603 y 719

Fuente: AMS, Diversos, 603 y 719 
Mapa 7: Instalaciones de la rivera de Galaroza (río Múrtiga) y otras, en término de Aracena (1497)

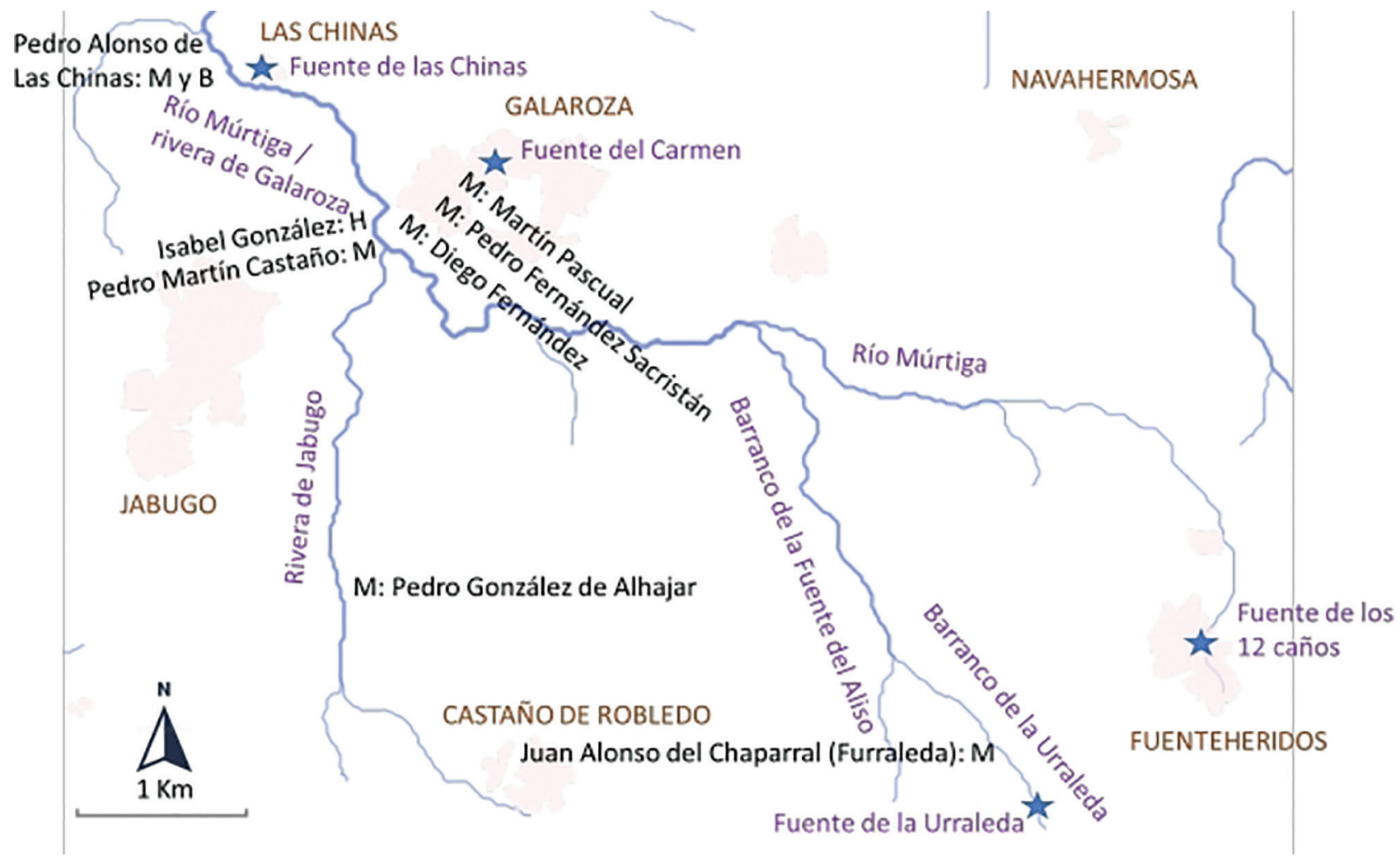

Fuente: AMS, Diversos, 724

de tal investigación, el de Martín Pascual; que lindaba con el abrevadero concejil, esto es, con la propia fuente (hoy en la avenida del Molino). Mientras que el siguiente, el de Pedro Sánchez, a continuación del anterior, pagaba tributo de solamente el diezmo, porque igualmente servía como bebedero del ganado local, según licencia para su edificación del consistorio aracenense.

La encuesta de 1497 de Galaroza no especifica dónde se encontraba el molino de los herederos de Pedro Alonso de Las Chinas, que contaba, además de la máquina para molturación de cereal, con un batán. Sin embargo, el segundo apellido, sin duda, hace referencia al topónimo Las Chinas, paraje del noroeste de Galaroza, junto al Múrtiga. Al noroeste de esta pedanía ${ }^{23}$, en la ribera del río, hay un rincón conocido como El Batán otros andurriales cercanos también hacen referencia a instalaciones hidráulicas, como El Martinete, al noroeste, o el barranco del Ingenio, al noreste-. Por ello, he emplazado dichos artefactos en tal sitio, y no con los restantes cachoneros; y por el hecho de que estuviesen en el propio Múrtiga. Aunque puede que este río se

\footnotetext{
23. Actualmente la fuente de Las Chinas se llama igualmente El Pilar de Abajo, como oposición al de Arriba (http://www.conocetusfuentes.com/ficha_ detalle.php?id_fuente=1955).
}

Tabla 7: Relación de inmuebles dedicados a actividades productivas en Galaroza, que rentaban al almojarifazgo de Aracena (1497), y su tipología: molinos harineros (M), molinos batanes (B) y azudes o heridos $(\mathrm{H})$

Instalación Tipo

Molinos de la rivera de Galaroza que nace cabo las casas de dicho lugar

Molino de Martín Pascual, difunto, linda con el abrevadero del concejo (hoy fuente de Nuestra Señora del Carmen)

Molino de Pedro Fernández Sacristán, linda con el anterior M

Molino de Catalina Gómez, mujer de Diego Fernández, escribano difunto de Cortegana, en la rivera de Galaroza, con 15 años, hecho por su marido en sus tierras

Molino de Pedro Martín Castaño, vecino de Almonaster, linda con el anterior

Herido de Isabel González, vecina del lugar

Molino de Juana Sánchez, mujer del difunto Juan Alonso del Chaparral, vecina de Aracena, Ilamado de la Hurraleda, linda con tierras de Juanito, vecino de Aracena; está todo en el abrevadero que es del ganado, que pertenece al concejo

Molino de los herederos de Pedro Alonso de Las Chinas, vecino del lugar, linda con tierras de Fernando Sánchez, también vecino del lugar, muy antiguo y no se sabe quién lo hizo; está en poder de Bartolomé Alonso, hijo de Pedro Alonso

Batán de los herederos del antedicho Pedro Alonso de Las Chinas, dentro de la misma casa del molino de arriba

\section{M}

Fuente, AMS Diversos, 724 
confundiese con la rivera de Galaroza, pues en la citada pesquisa, como he adelantado, se agruparon todos los inmuebles en un mismo epígrafe así llamado. Por otra parte, el Múrtiga vuelve a llamarse Galaroza a su paso por La Nava, sita curso abajo, de nuevo al noroeste de Las Chinas, como luego veremos.

El molino de la Hurraleda, propiedad de Juana Sánchez, mujer del difunto Juan Alonso del Chaparral topónimos al noroeste de La Nava, norte de Cumbres de Enmedio y este de Cumbres Mayores-, según la pesquisa de 1491 aracenense que arriba vimos, se hallaba en la rivera del mismo nombre o de la Furraleda. La fuente de la Urraleda está en la carretera de Fuenteheridos a Castaño del Robledo, a unos dos kilómetros de la primera localidad; en el actual barranco de la Urraleda, que se forma al norte de Alájar y discurre al este de Castaño del Robledo, entre ésta y Fuenteheridos, donde nace el Múrtiga, como sabemos, esto es, al sureste de Galaroza, y muere en el barranco de la Fuente del Aliso, que a su vez desemboca en el susodicho Múrtiga ${ }^{24}$.

\section{Hinojales}

Las pesquisas de 1491 y 1497 (Tabla 8 y Mapa 8) dan cuenta, también por separado, como en el caso anterior, de los ingenios ubicados en otra aldea aracenense: Hinojales. Tanto en la rivera que lleva su nombre -que va a dar a la de Huelva, por su ribera izquierda o norte, la contraria a la que desembocan los otros cursos de agua que hemos visto-, como en el arroyo de la Corte, que muere en ella. Este pueblo se halla al norte de Aracena, y al sureste de Cumbres Mayores, más cerca de la última que de la primera.

La información de 1497 da comienzo por este último curso de agua, hoy conocido como barranco de la Corte, que nace al noroeste de la población, para describir un arco sobre la misma por el norte hasta el noreste, y acabar al sureste en la rivera de Hinojales, como he dicho. De estos artefactos, caso del primero, o molino y herido de Martín Alonso ${ }^{25}$, el Monje, se dice que lindaban con tierras suyas, y no tenían vega ni isleta. Esto es, como se apunta para el de Alonso Ramos, carecían de vega realenga; pues, como dije, el cuérnago estaba excavado en tierras del titular del inmueble, no en las de domino público.

\footnotetext{
24. http://www.conocetusfuentes.com/ficha_detalle.php?id_fuente=1928.

25. Le fue dada licencia para un molino de pan en el arroyo de la Corte, camino de Fregenal, en 1482
}

\section{La Nava}

Esta localidad, situada al norte de Cortegana, y al noroeste de Galaroza, poco más arriba de Las Chinas, fue en el siglo XV una aldea corteganesa, de modo que sus molinos pagaban tributos en su almojarifazgo, y están recogidos, a tal efecto, en una pesquisa de 1497 (Tabla 9), como las arriba vistas. Donde se dice que el río que por allí pasaba era el Galaroza, hoy conocido como Múrtigas, como hemos visto para la propia Galaroza.

El primero de los inmuebles era llamado molino del Fresno, pertenecía a Juan Romero y lindaba con el de Santa María; contaba con una vega debajo de su cabecera, de su propiedad ${ }^{26}$. Al noroeste de La Nava, y al sur de los meandros del Múrtiga, hoy en término de Cumbres de San Bartolomé, se encuentra el puerto de Santa María, donde puede que estuviesen estos molinos, algo alejados del pueblo, a unos $5 \mathrm{~km}$ en línea recta, pues de algunos otros se dice que se hallaban cercanos al mismo. Sobre todo, el último del listado, el batán de la mujer de Diego Fernández, que se localizaba junto a La Nava. De modo que, entre el primero, sito en el límite municipal con Cumbres de S. Bartolomé, y este último, voy a colocar todos los artefactos, agrupándolos según indica la documentación. Otro de los molinos era el del escribano de Cortegana Juan Girandillo, llamado de Los Nogales, ya que contaba con una vega con ciertos nogales; lindaba con el de Juan de Medina, era muy antiguo y lo había comprado de muchos dueños. Pues bien, en 1503 se le dio permiso para trasladarlo algo más abajo, al terreno más firme de su presa; allí se dice de nuevo que lindaba por abajo (aguas abajo, Mapa 9) con el de Juan de Medina, escribano de Cumbres Mayores; y, por encima, con el de Gonzalo Vázquez, lugarteniente del escribano concejil sevillano, que no aparece en la pesquisa de 1497, pero sí en una licencia que se le concedió en 1499 para trasladar asimismo este otro ingenio unos 15 pasos más delante, y transformarlo en uno de dos ruedas y dos asientos, y, en su solar, construir un batán.

\footnotetext{
26. El segundo era el molino de Las Juntas, que lindaba con el de Juan de Medina; $1 / 3$ propiedad de Pedro Martín Soriano, vecino de la villa; con merced de 1478 de Sevilla, hecha al escribano de La Nava Diego Galíndez, que disponía que pagase anualmente $20 \mathrm{mrs}$. de tributo, y no lo pudiese vender sin permiso de la ciudad; los otros 2/3 eran de Diego Galíndez y de Juan Martínez, suegro de Pedro Martín Soriano. Sin embargo, lo que consta es una licencia de ese año al escribano Diego Galíndez. AMS, Acta Capitular (AC) 1478 novdic fol. $3 r$.
} 
Tabla 8: Relación de inmuebles dedicados a actividades productivas, que rentaban al almojarifazgo de Hinojales, comprendido en el de Aracena (1491 y 1497) y su tipología: molinos harineros (M), molinos batanes (B) y azudes o heridos $(\mathrm{H})$

\begin{tabular}{lc}
\hline \multicolumn{1}{c}{ Inmueble } & Tipo \\
\hline Molinos del arroyo de la Corte & \\
\hline Herido del citado Martín Alonso, linda con el anterior & $\mathrm{M}$ \\
Molino y herido de Fernando Martínez y sus herederos, linda con el anterior & $\mathrm{H}$ \\
Molino de Juan Martínez, cestero, linda con el anterior & $\mathrm{M} \mathrm{y} \mathrm{H}$ \\
\hline
\end{tabular}

Molinos de la rivera de Hinojales

Molino que hizo Alonso Ramos, gallego, en sus tierras, lo poseen ahora sus hijos M

Fuente: AMS, Diversos 610, 726

Mapa 8: Instalaciones de la rivera de Hinojales y otras, en término de Aracena (1491-1497)

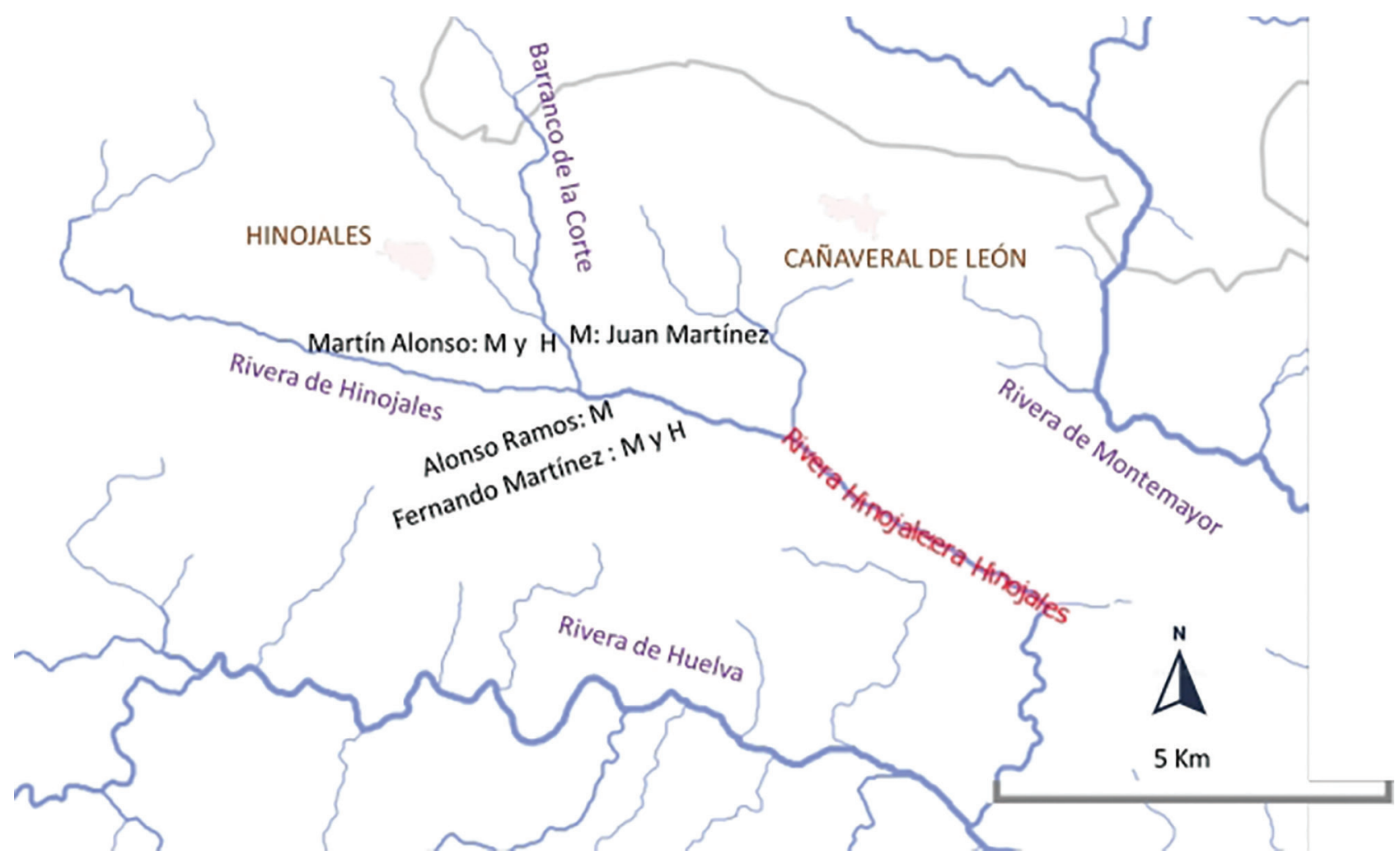

Fuente: AMS, Diversos 610, 726

\section{Cumbres Mayores}

El pueblo se halla al noroeste de Hinojales y al noreste de La Nava. Como esta última, y la siguiente de Cumbres de San Bartolomé, solamente aparece en la pesquisa de 1497 (Tabla 10), pero con un buen número de instalaciones molinares, repartidas entre la rivera (hoy arroyo) del Sillo, al norte, y el río Múrtiga y su afluente la rivera (hoy barranco) de Riofrío, al suroeste, que desemboca justo en el único punto por donde este río fluye por el término de Cumbres Mayores, de manera que el resto del curso, en sus dos márgenes, discurre por Cumbres de San Bartolomé. Además, dicho Riofrío sirve de límite natural entre los términos de ambas Cumbres, por lo que los molinos de las Mayores deberán colocarse en su ribera izquierda.

\section{Rivera del Sillo}

Este epígrafe de la pesquisa de 1497 dice que el Sillo nacía en el término de Fuentes (de León, al NE) y Segura (de León, al E); en su día en el maestrazgo de Santiago (fuera de la tierra de Sevilla, por tanto), y hoy en la pro- 
Tabla 9: Relación de molinos en la rivera de Galaroza, que rentaban al almojarifazgo de La Nava, incluido en el de Cortegana (1497) y su tipología: molinos harineros (M), molinos batanes (B) y azudes o heridos (H)

\begin{tabular}{lc}
\hline \multicolumn{1}{c}{ Inmueble } & Tipo \\
\hline Molino de Juan Romero, llamado del Fresno, linda con el molino de Santa María & M \\
$\begin{array}{l}\text { Molino de Las Juntas, en parte propiedad 1/3 de Pedro Martín Soriano, vecino de la villa, los otros 2/3 eran de Diego Galín- } \\
\text { dez y de Juan Martínez, suegro de Pedro Martín Soriano, linda con el molino de Juan de Medina }\end{array}$ & M \\
Molino de Juan Girandillo, escribano, llamado de Los Nogales, linda con el de Juan de Medina & M \\
Molino de la madre de Fernando González, escribano, linda con el molino de Juan de Medina & M \\
Molino de la mujer de Diego Fernández, escribano difunto, cerca de La Nava, linda con el molino del alcaide Trujillo & M \\
Otro molino de la anterior & M \\
Otro molino de la anterior, llamado del Hornillo & M \\
Molino de Fernando Domínguez, llamado de Jaén, en La Jovera, linda con el molino de las Juntas & M \\
Batán de la mujer del susodicho Diego Fernández, junto a La Nava, linda con el batán de Juan de Medina & B
\end{tabular}

Fuente: AMS, Diversos, 727

Mapa 9: Instalaciones de la rivera de Galaroza (río Múrtiga), en La Nava, en término de Cortegana (1497)

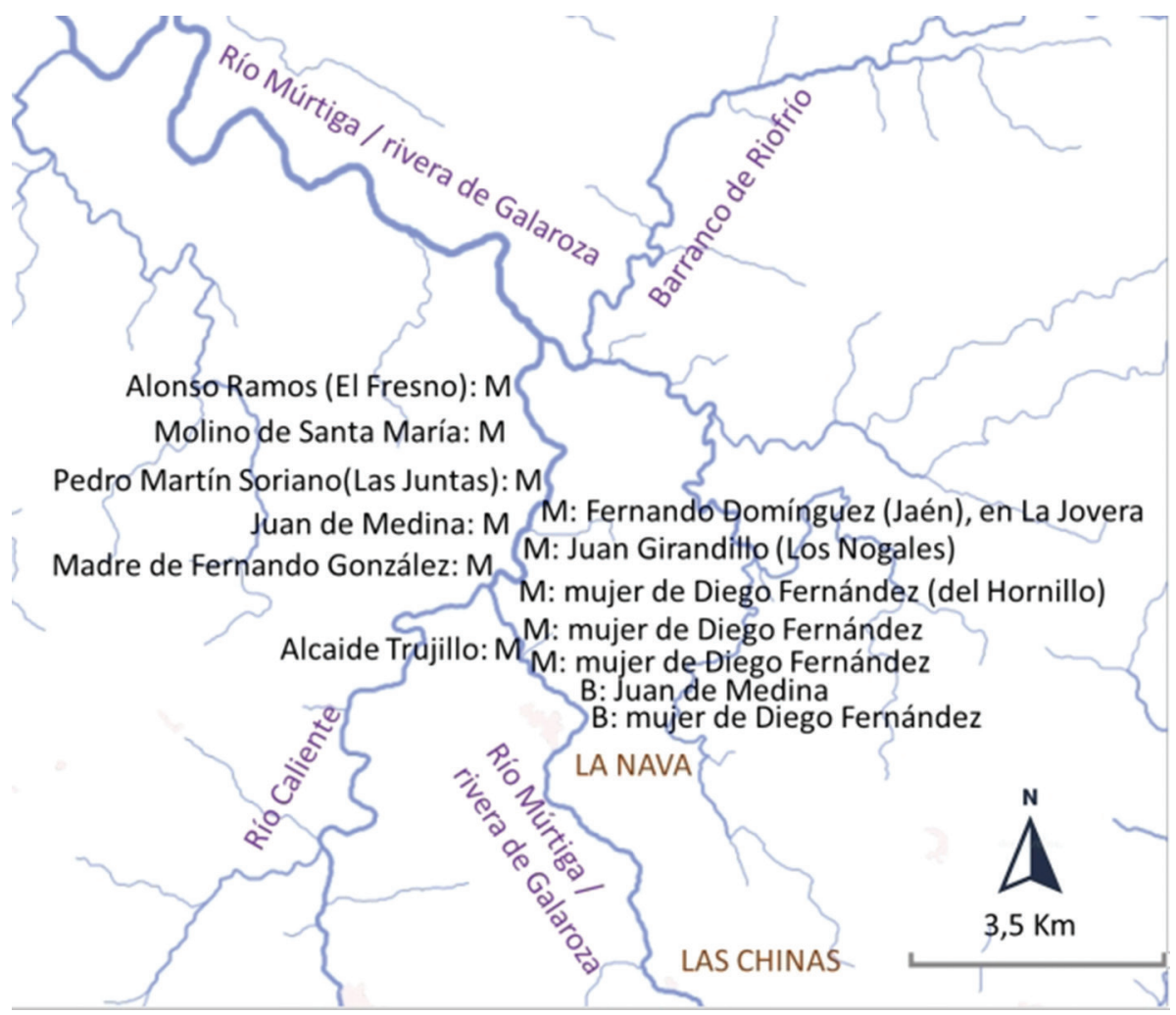

Fuente: AMS, Diversos, 727

vincia de Badajoz. Actualmente, divide las provincias onubense y pacense. Como en otros casos anteriores, sus ingenios aparecen ordenados según su situación, curso abajo, y conforme se avanza en el listado para casi todos ellos, menos los dos últimos, se indica que estaban radicados a continuación del precedente. Del penúltimo, el herido de Juan Benito, el viejo, se dice que se hallaba en el linde del primer molino de esta rivera; $y$, si no lo habían colocado en el primer lugar de la lista, habría sido por- que se añade de él que hacía un año que se hallaba en construcción, de modo que no interesaría a efectos fiscales, para lo que fue redactada la citada relación, pues todavía no pagaría tributo alguno. Así, este primer molino, llamado Redondo, de Mecía Gómez, se detalla que era muy antiguo y que no había estado en producción hasta hacía un año; se radicaba en sus tierras, lindero con la ladera de Regaza, sin isleta ni vega realengas. El Mapa 10 lo he situado en el confín con la actual provincia de Ba- 
Mapa 10: Instalaciones de las riveras de Múrtigas y Sillo, en Cumbres Mayores y Cumbres de S. Bartolomé (1491-1497)

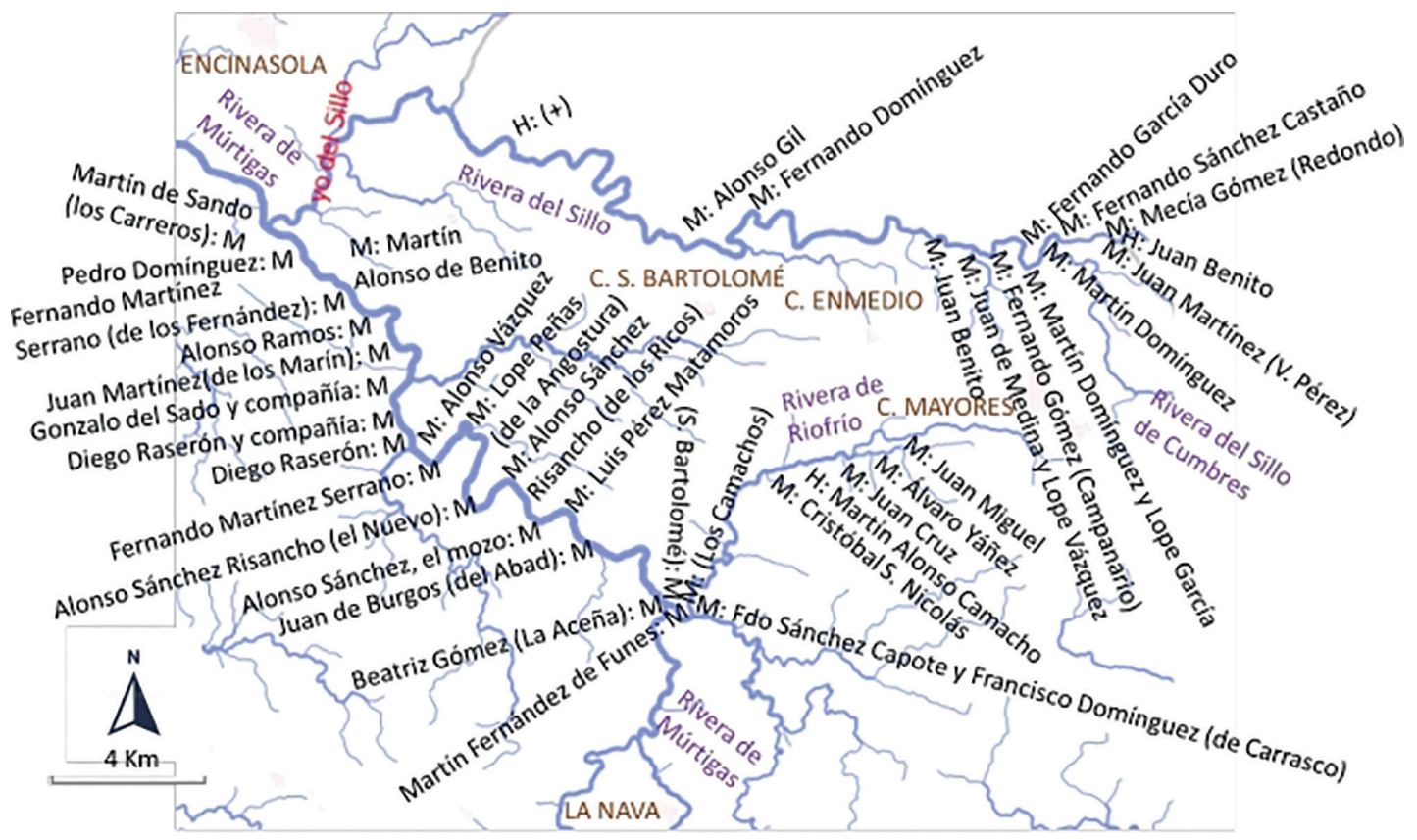

Fuente: AMS, Diversos, 721-722

dajoz. Algunos de estos inmuebles los he emplazado en la ribera derecha, por cuestión de espacio, pero lo más probable es que todos estuviesen en la izquierda, pues este curso de agua marca los límites jurisdiccionales con los concejos pacenses de Fuentes de León e Higuera la Real, este último asimismo perteneciente a los pueblos de Sevilla, como Cumbres Mayores. Con el citado molino de Mecía Gómez lindaba el segundo, llamado de Vasco Pérez, quien lo había legado para que le fuesen dichas 50 misas anuales tras su muerte, y que en ese momento lo poseía Juan Martínez; en sus tierras, sin isleta ni vega, como casi todos ellos. Del tercero, de Fernando Sánchez Castaño, se indica que no estaba en sus tierras, sino en la dehesa del concejo; de modo que ésta ocuparía buena parte de su término norte - en la actualidad, ribereña a los meandros del Sillo, se encuentra la Dehesa de Abajo-. Y, del cuarto, del albañil Martín Domínguez, se expone que se hallaba en el reguero del concejo de la villa. Por todo lo dicho, este reguero, con toda probabilidad, sería el actual arroyo del Sillo de Cumbres (del concejo, por tanto), y el molino en cuestión estaría emplazado en su confluencia con el arroyo del Sillo, donde desembocaba. Del antepenúltimo artefacto (el 12 del listado), el último del que sabemos su emplazamiento y que lindaría con el término municipal de Cumbres de Enmedio, cuyo almojarifazgo pertenecía al de su vecina San Bartolomé, el segundo de Fernando Sánchez Castaño, se expone que se levantaba en el Castrejón. En un meandro al norte de
Cumbres de Enmedio, en este ayuntamiento, pero justo donde está el actual límite municipal con las Mayores, en el margen derecho del Sillo, en la provincia de Badajoz, se localiza el poblado celta de Castrejón de Capote. Además, el molino precedente, el decimoprimero del listado, perteneció a Fernando Sánchez Capote. Todo ello no hace sino corroborar que esta relación de molinos colindantes se comenzó en el curso alto del Sillo, para continuar corriente abajo.

De los restantes solamente hay que indicar algo más sobre su propiedad: el de Fernando García Duro (5º) estaba también en la dehesa concejil; el de Martín Domínguez y Lope García (6o), se erigió en tierras realengas; los de Fernando Gómez (7), o del Campanario, y el de Fernando Gómez Barbas, y Fernando Gómez de Álvaro Gómez (8º), en sus tierras particulares; $y$, el de Juan de Medina y Lope Vázquez ( $\left.9^{\circ}\right)$, ubicado en Val de Pelayo, vuelve a aparecer en la dehesa del concejo; el cual había sido construido gracias a una licencia dada por el mismo 18 años atrás a Juan Martínez Calas, a cambio de $5 \mathrm{mrs}$. de tributo anuales, pero como no lo edificó lo había tomado Lope Vázquez del consistorio hacía 5 años, con dicho tributo. El último lugar (13) lo ocupa el herido viejo de los hijos del bachiller Fernando Bravo, que no estaba comenzado a construir (reconstruir), y no se indica dónde se encontraba. 
Tabla 10: Relación de inmuebles dedicados a actividades productivas, que rentaban al almojarifazgo de Cumbres Mayores (1497) y su tipología: molinos harineros (M), molinos batanes (B) y azudes o heridos $(\mathrm{H})$

\begin{tabular}{|c|c|}
\hline Instalación & Tipo \\
\hline \multicolumn{2}{|l|}{ Molinos de la rivera de Sillo que nace en el término de Fuentes (de León) y Segura (de León), maestrazgo de Santiago } \\
\hline Molino de Mecía Gómez, llamado de Redondo, linda con la ladera de Regaza & M \\
\hline Molino de Juan Martínez, llamado de Vasco Pérez, que lo dejó por herencia para que dijeran cada año 50 misas, linda con el anterior & M \\
\hline Molino de Fernando Sánchez Castaño, linda con el anterior, muy antiguo, en la dehesa del concejo de la villa & M \\
\hline Molino de Martín Domínguez, albañil, linda con el anterior, muy antiguo, en el reguero del concejo de la villa & M \\
\hline Molino de Fernando García Duro, linda con el anterior, en la dehesa del concejo de la villa & M \\
\hline Molino de Martín Domínguez y Lope García, linda con el anterior & M \\
\hline Molino de Fernando Gómez, Ilamado del Campanario, linda con el anterior & M \\
\hline Molino de Fernando Gómez Barbas, linda con el anterior, lo poseen el susodicho y Fernando Gómez de Álvaro Gómez & M \\
\hline Molino de Juan de Medina y Lope Vázquez, en Val de Pelayo, en la dehesa del concejo, linda con el anterior & M \\
\hline Molino de Juan Benito, el mozo, linda con el anterior, a medio edificar, solo la cabecera & M \\
\hline Molino de Fernando Sánchez Capote, en dicho lugar, linda con el anterior & M \\
\hline Molino de Fernando Sánchez Castaño, en el Castrejón, linda con el anterior & M \\
\hline Herido de Juan Benito, el viejo, está en el linde del primer molino de esta rivera & $\mathrm{H}$ \\
\hline Herido viejo de los hijos del bachiller Fernando Bravo & M \\
\hline
\end{tabular}

Molinos de la rivera de Múrtigas

Molino de Fernando Sánchez Capote y Francisco Domínguez, llamado de Carrasco

Molino de Martín Fernández de Funes, linda con el anterior, dentro de la madre de la rivera

Molino de los Camachos, linda con el anterior,

Molino de la anterior propietaria, de S. Bartolomé, linda con el anterior

Molinos de la rivera de Riofrío

Molino de Álvaro Yáñez, en su tierra, junto con el molino de Juan Miguel

Molino de Juan Cruz, linda con el anterior

Fuente: AMS, Diversos, 721

\section{Múrtigas y Riofrío}

Las construcciones hidráulicas cumbreñas del Múrtigas (Tabla 10) estarían, como he adelantado, en un pequeño punto de este río donde desemboca el barranco o rivera de Riofrío. También se manifiesta que lindaban entre sí, por lo cual situaré la primera en dicha confluencia -el molino llamado de Carrasco, de Fernando Sánchez Capote, topónimo visto más arriba, y Francisco Domínguez-, para seguir con las restantes aguas abajo. Del segundo, de Martín Fernández de Funes, se informa que estaba en la madre de la rivera, esto es, en el curso fluvial, por lo que, a diferencia de los restantes, puede que no tuviese regato y consistiese en una aceña con eje horizontal. Claramente tuvo esta condición el cuarto molino, el de
Beatriz Gómez, pues se llamó de La Aceña. Del quinto no se anota el propietario, pero sí su nombre, San Bartolomé, muy relacionado con el pueblo vecino ${ }^{27}$.

En cuanto a la rivera de Riofrío, sus molinos igualmente estuvieron contiguos, por lo que situaré el primero de la lista curso arriba (Tabla 10), para seguir con los restantes hacia su desembocadura en el Múrtiga.

\footnotetext{
27. Puede que en este curso de agua hubiese algún ingenio más, pues en 1495 el albañil Juan García obtuvo licencia para un molino de pan de 2 asientos en él, cerca de la ermita de S. Bartolomé. AMS, PM 1495, nº 187.
} 


\section{Cumbres de San Bartolomé}

En su pesquisa de 1497, al contrario del caso anterior, hay más inmuebles sitos en el Múrtigas que en el Sillo, por lo que aparecen en esta prelación (Tabla 11). Aunque, no obstante, yo comenzaré, al contrario, para mantener el mismo orden que en el pueblo vecino.

\section{Sillo}

Allí apenas se cuentan tres molinos -el segundo del alguacil Juan Sánchez y un compañero suyo ${ }^{28}-$, y tres heridos. Los voy a colocar en la ribera derecha, por cuestiones de espacio, aunque estarían en la izquierda, como en Cumbres Mayores, y de forma correlativa, curso abajo, como siempre; si bien solamente del herido de Martín Alonso de la Miroga y Juan Marqués, que se reacondicionaba en esos momentos, pues correspondía a un molino antiguo anteriormente existente, se dice que lindaba con la construcción anterior, el molino de Alonso Gil ${ }^{29}$. El siguiente ( $\left.4^{\circ}\right)$ era un herido que llamaban de los Fernández, derruido, sin casa ni piedras (muelas). Mientras que, del último, identificado por una señal en forma de cruz, solamente se dice que no tenía edificio alguno. Se suele repetir que no había isletas ni vegas realengas.

\section{Múrtiga}

En él voy a situar los 17 inmuebles correspondientes, todos molinos harineros, indistintamente en ambas riberas, pues pertenecían a ese concejo, desde la desembocadura de Riofrío, como sabemos, hasta el término de Encinasola, que comienza en la confluencia de este río y el Sillo. Seguiré el mismo sistema que en los casos anteriores, los colocare en el orden en que aparecen, corriente abajo, siempre que la fuente no indique que se ubicaron en otro sitio; como pasa con el molino de los Carreros, de Martín de Sando y sus compañeros, que aparece en séptimo lugar, pero que lo he situado en el Mapa 10 el último, al especificarse que estaba junto al de Pedro Domínguez, que ocupa el postrero puesto en la relación

28. En 1494 Juan Sánchez Risancho y Juan Martín Chamorro obtuvieron permiso para hacer un molino de pan en la rivera del Sillo, junto al charco de Domingo Caro y la dehesa de la aldea.

29. En 1494 se dio una licencia al escribano Alfonso Gil, el mozo, para hacer un molino de pan, pero estaba en la rivera del Múrtiga; así como otra para reconstruir otro ingenio de Gonzalo García, Fernando Serrano y Alfonso Gil, junto a otro suyo de algo más arriba, asimismo en el Múrtigas, por tener la presa rota. Ese año, igualmente en Cumbres de S. Bartolomé y en el Múrtigas, se dio una autorización para otro molino harinero a Bartolomé Pérez, Gonzalo Pérez y Ruy González, vecinos de Encinasola, del que no he encontrado rastro en las pesquisas. documental - sin embargo, a poco de entrar el Múrtigas en término de Cumbres de S. Bartolomé, al norte del río hay un puerto llamado del Carrero- ${ }^{30}$. Además, en esta ocasión no siempre se dice que estuviesen correlativos.

Antes, habrá que entresacar algunos datos importantes. El primero es el molino de Juan de Burgos - del que más abajo se dice que se llamaba del Abad; entrado el Múrtigas en el término de Cumbres de S. Bartolomé, en la ribera derecha, existe un paraje llamado Llano de Burgos-, vecino de Encinasola, que lo había edificado con Alonso de Flores, clérigo de Encinasola, junto a tierras de Juan Sánchez. Del segundo, de Luis Pérez Matamoros, se indica que lindaba con otros de ese concejo y con tierras de Juan Gil - uno de los parajes del Múrtigas, vecino a un meandro, tiene en la actualidad el nombre de Gonzalo Gil, lo que puede que no sea casual-; y, lo más importante, poseía una vega grande que sembraba, con el paso libre, por estar en la dehesa - al norte de estos meandros, ya hacia el interior del término, discurre el arroyo de la Dehesa, que muere en dicho río ${ }^{31}$ - junto a las tierras del antedicho Matamoros. Algo parecido pasa con el tercero, de Alonso Sánchez el mozo y sus compañeros, próximo a tierras de Juan López, con una vega que era sembrada, pero con un paso común. Mismo caso que los dos molinos contiguos $\left(4^{\circ}-5^{\circ}\right)$, el de los Ricos y el Nuevo, de Alonso Sánchez Risancho y sus compañeros, con una vega entre la cabecera y la rivera de siembra y paso comunal; y que el colindante $\left(6^{\circ}\right)$, de la Angostura, de Lope Peñas y los suyos, del que se aclara que el paso libre se podía hacer tras cosechar las semillas. Lo que se especifica también en el de Fernando Martínez Serrano ( $\left.8^{\circ}\right)$, que colindaba con tierras del concejo. El molino del licenciado Diego Raserón (10) lindaba con el de la huerta. Como el de los de Marín (13º), de Juan Martínez, clérigo, contaba con una huerta propia, puede que fuese el que estuviese junto al anterior. Aunque también tenía huerta el de los Fernández $\left(15^{\circ}\right)$, de Fernando Martínez y sus compañeros.

\footnotetext{
30. A este molino le fue dada su licencia en 1495. Otro fue el de Alonso Vázquez que lindaba con el de la Angostura, que abajo veremos, era nuevo, pues hacía 3 años lo había hecho en sus tierras; con permiso para él y sus compañeros del año 1496. Pues bien, en dicha autorización consta que Juan Martín Chamorro, Alfonso Vázquez, Fernán Sánchez y Gonzalo Sánchez podían edificar un Molino de pan, en la rivera de Múrtiga, en la vega de Torre (AMS, PM 1496, $\left.n^{0} 55\right)$. Hacia el final de los meandros del Múrtigas, se encuentran las ruinas del castillo de Torres y el paraje Casa de Torres.

31. En 1495 le fue concedida autorización a Martín Alfonso, Martín Domínguez, Andrés Miguel y Bartolomé Sánchez para 2 molinos de pan, en este arroyo de la Dehesa, uno en el Charco, otro en el Fresnillo. Mientras que en 1496 Bartolomé Domínguez la obtuvo para otro en el Charco de la Olla, camino de la rivera de Múrtiga y Aroche. AMS, PM 1495, $\mathrm{n}^{\circ} 186$ y 1495, $\mathrm{n}^{0} 75$.
} 
Tabla 11: Relación de inmuebles dedicados a actividades productivas, que rentaban al almojarifazgo de Cumbres de San Bartolomé (1497) y su tipología: molinos harineros (M), molinos batanes (B) y azudes o heridos (H)

\begin{tabular}{|c|c|}
\hline Inmueble & Tipo \\
\hline \multicolumn{2}{|l|}{ Molinos de la rivera de Múrtigas } \\
\hline Molino de Juan de Burgos en dicha rivera, vecino de Encinasola, linda con tierras de Juan Sánchez & M \\
\hline Molino de Luis Pérez Matamoros en dicha rivera, linda con otros de ese concejo y con tierras de Juan Gil & M \\
\hline Molino de Alonso Sánchez el mozo y sus compañeros, en dicha rivera, linda con tierras Juan López & M \\
\hline Molino de Alonso Sánchez Risancho y sus compañeros, llamado de los Ricos, linda con el anterior & M \\
\hline Molino de Alonso Sánchez y sus compañeros, llamado el Nuevo & M \\
\hline Molino de Lope Peñas y sus compañeros, llamado de la Angostura & M \\
\hline Molino de Martín de Sando y sus compañeros, Ilamado de los Carreros, linda con el molino de Pedro Domínguez & M \\
\hline Molino de Fernando Martínez Serrano, linda con tierras del concejo & M \\
\hline Molino de Alonso Vázquez, linda con el de la Angostura & M \\
\hline Molino del licenciado Diego Raserón, linda con el de la huerta & M \\
\hline Molino del anterior con algunos compañeros, linda con el de arriba & M \\
\hline Molino de Gonzalo del Sado y sus compañeros, linda con el anterior & M \\
\hline Molino de Juan Martínez, clérigo, llamado de los de Marín, linda con el anterior & M \\
\hline Molino llamado de Alonso Ramos, linda con el anterior & M \\
\hline Molino de Fernando Martínez Serrano y sus compañeros, llamado de los Fernández & M \\
\hline Molino de Martín Alonso de Benito, llega hasta la rivera & M \\
\hline Molino de Pedro Domínguez, linda con el anterior & M \\
\hline
\end{tabular}

\section{Molinos de la rivera de Sillo}

Molino en dicha rivera de Fernando Domínguez, vecino de las Cumbres Mayores

Molino de Alonso Gil

Herido de molino que linda con el anterior, lo comenzaron a hacer Martín Alonso de la Miroga y Juan Marqués en tierras de este último

Fuente: AMS, Diversos, 722

\section{Higuera la Real y Fregenal de la Sierra}

Antes de proseguir hacia el oeste por el Múrtigas y otros cursos, debemos detenernos puntualmente al norte de las diversas Cumbres, al norte del Sillo, por tanto, donde se encuentra Higuera (hoy la Real), en la provincia de Badajoz, pero en el siglo XV perteneciente a la ciudad de Sevilla, dentro del almojarifazgo de Fregenal de la Sierra. Por lo que aparece entre las pesquisas de 1497 (Tabla 12), donde se dice que sus molinos salían de la fuente del Gargallo. Hoy fuente Gargallón, la cual se halla en el barranco los Molinos de Gargallón, que discurre de norte a sur, al este de esa villa y cercano a ella; hasta morir en el arroyo de Moriano, afluente por la ribera derecha del Sillo, en el que desemboca en el arriba visto Castrejón de Capote. De uno de los molinos de esta relación del Gargallo, de los here- deros de Gonzalo Sánchez del Poso, vecinos de Cumbres Mayores, se dice tenía dos ruedas, una huerta de nogales y que entraba en el arroyo del Álamo; éste fluye al este del barranco de los Molinos de Gargallón, para morir en el barranco de San Lázaro; que es la parte final del arroyo de las Huertas y de las Piñuelas, que, como veremos, pasa al este de Fregenal, pegado al pueblo, y confluye asimismo con el arroyo de Moriano. Los restantes ingenios se radicaban en la rivera de la fuente de las Huertas. Al norte de Fregenal, en su término municipal, muy cercano al este de Higuera la Real, y próximo al casco urbano frexnense, discurre el arroyo de Rocón, más adelante llamado de las Huertas y luego de Las Piñuelas, que acabo de citar, en el que está la fuente de la Aceña. Varios de los topónimos del lugar contienen el término huerta, incluso uno de ellos, de un paraje junto al arroyo, se denomina Huertas de la Ribera. El último 
Tabla 12: Relación de inmuebles dedicados a actividades productivas, que rentaban al almojarifazgo de Higuera la Real, comprendido en el de Fregenal (1497) y su tipología: molinos harineros (M), molinos batanes (B) y azudes o heridos (H)

\begin{tabular}{|c|c|}
\hline Inmueble & Tipo \\
\hline \multicolumn{2}{|l|}{ Molinos que salen de la fuente del Gargallo (Gargallón) } \\
\hline Molino propiedad de Sevilla, Ilamado de Encima, & M \\
\hline Molino de Isabel Rodríguez, mujer de Alonso Sánchez, bachiller, Ilamado La Aceña & M \\
\hline Molino propiedad de Sevilla, Ilamado de las Almenas, linda con el anterior & M \\
\hline Molino de Gonzalo Rodríguez, hijo de Benito Miguel, linda con el anterior & M \\
\hline Molino de Juan García Jara, vecino de Fregenal, Ilamado de las Huertas & M \\
\hline Molino de Juan Martínez Franco, linda con el anterior & M \\
\hline Molino de Juan Martínez del Aldán, linda con el anterior & M \\
\hline Molino de Martín Gil, linda con el anterior & M \\
\hline Molino de Alonso Gómez, linda con el anterior & M \\
\hline Molino de Fernando Fernández, linda con el anterior & M \\
\hline Molino de Juan Serrano y de Juan Simón del Bodonal, linda con el anterior & M \\
\hline Molino del comendador Juan García Torquemada, vecino de Fregenal, Ilamado del Nogal & M \\
\hline Molino de Fernando de Soto de Jerez, linda con el anterior & M \\
\hline Molino llamado de los Arcos que es de las beatas de Alonso Mateos, linda con el anterior & M \\
\hline Molino de dicho Juan García Jara, llamado de las Bravas & M \\
\hline Molino de los herederos de Vasco Chamorro, de Fregenal, llamado Nuevo & M \\
\hline Molino de Pedro de Morales, vecino de Fregenal, linda con el anterior & M \\
\hline Molino de García Gómez, vecino de Cumbres Mayores, llamado de la Torre & M \\
\hline Molino también de García Gómez, llamado del Barranco & M \\
\hline Molino de las beatas de Benito Miguel y Alonso Mateos, llamado el de Rengadillo & M \\
\hline \multicolumn{2}{|l|}{ Molino llamado el de Mingueta, del antedicho Juan García Jara, linda con el anterior, muy antiguo; sin merced ni tributo } \\
\hline Molino de los herederos de Gonzalo Sánchez Poso, vecinos de Las Cumbres Mayores, con 2 ruedas, entra en el arroyo del Álamo & M \\
\hline Herido de molino de Fernando Francisco & $\mathrm{H}$ \\
\hline Molino de Gómez González, llamado de la Alcoba, linda con el anterior & M \\
\hline Molino de Andrés García, herrero, llamado de la Jara, linda con el anterior & M \\
\hline Molino de Juan Rodríguez Perales, de Rubiales, linda con el anterior & M \\
\hline Molino de Juan Martínez del Alda, vecino de Alda, Ilamado del Risco del Castrejón & M \\
\hline
\end{tabular}

\section{Molinos de la rivera de la fuente de las Huertas}

Molino del bachiller Alonso Sánchez, llamado el Molinillo M M

Molino de Gonzalo Pérez Hadraga, linda con el anterior, este molino estaba en la madre y atravesaba el camino real que iba a Jerez (de los $\quad$ M Caballeros)

Molino de Martín de Pino, escribano, linda con el anterior $\quad$ M

Molino de Alonso Gómez, llamado de la Huerta de los Moritos, debajo del anterior $\quad$ M

Molino de Pedro Pascual $\quad M$

Molino de Diego Vázquez $\quad M$

Molino de Juan Gallego, en la rivera de la fuente del Cincho $\quad M$

Fuente: AMS, Diversos, 725 
molino de la inquisición de 1497, al final del epígrafe de esta rivera de la Fuente de las Huertas, se dice que estuvo en la rivera de la fuente del Cincho. Este arroyo del Cincho acaba en el Sillo, y es la parte final del arroyo del Alcornoquito, que nace al noroeste de Higuera la Real y corre paralelo al barranco de los Molinos de Gargallón.

\section{Fuente del Gargallo}

Del primer molino de este curso de agua, de un total de 28 artefactos, llamado de Encima, que he colocado, por tanto, en su cauce superior, se dice que era del concejo hispalense. Esto es, que en lugar de pertenecer a un particular y pagar un tributo al almojarifazgo, o estar exento, lo poseía Sevilla, que lo arrendaba al mejor postor, y su renta era contenida dentro del almojarifazgo local higuereño, incluido en el de Fregenal. A partir de este ingenio, de casi todos los restantes se indica que lindaban con el precedente, así pues, los he colocado siguiendo este orden, corriente abajo, como en los casos anteriores. El segundo, de Isabel Rodríguez, mujer del bachiller Alonso Sánchez, se conocía como La Aceña, por lo que sería de esta variante, frente a los restantes de rodezno, y estaría sobre la madre del barranco; aunque se apunta que había sido erigido en su tierra y no tenía huerta ni isleta en lo realengo. Algo que se repite para casi todos los posteriores. El tercero, de las Almenas, era, como el primero, de Sevilla, con un pedazo de huerta; algo con lo que contaban algunos otros. Como se aprecia en el Mapa 11, el último, de Juan Martínez del Alda, vecino de Alda, edificado en un herido antiguo, se llamó del Risco del Castrejón. Como vimos, este barranco Gargallón acaba en el arroyo de Moriano, que, poco más abajo, desemboca en el Sillo, justo en el poblado celta de Castrejón de Capote. Lo que corrobora que estos listados molinares se redactaron ordenada y correlativamente desde las vegas altas aguas abajo.

\section{Rivera de la fuente de las Huertas}

De nuevo se apunta en casi todos los inmuebles que estaban unos linderos con los otros; pero, a diferencia de La Higuera, aquí muchos usurpaban terrenos públicos o realengos. De este modo, en el segundo apunte, del molino de Gonzalo Pérez Hadraga, se explica que hacía ocho años, cuando eran alcaldes Alonso Gómez y Alonso López, se les comunicó que algunas huertas, molinos y otras casas de los vecinos del lugar estaban en la madre de esta rivera, lo que perjudicaba al concejo. De manera que se puso a seis hombres juramentados para que la demarcaran y lo que hallasen entrado en tierra de realengo lo cortasen y amojonasen; y quedase libre la madre con sus veredas cerca del agua, según antiguamente se hizo. Dichos hombres encontraron que este molino estaba en la madre, atravesaba el camino real de Jerez (de los Caballeros, hoy paralelo al arroyo), y que el campo y parte de la casa se hallaban dentro de lo realengo. Cuando actuaron nuevos alcaldes, Pedro Díaz y Alonso Gallego, el viejo, fueron junto con otras personas diputadas por el concejo para marcar lo realengo, desde la dehesa del concejo hasta el arroyo de Encima; entre otras tierras, las de dicho molino. Lo que dio lugar a un pleito entre Gonzalo Pérez y dicho consistorio. Del quinto molino, de Pedro Pascual, comenzado a erigir recientemente, se hace mención de que el hoyo en el que se iba a hacer estaba asimismo en lo realengo, junto a la madre y el agua, sin licencia; aunque el susodicho había jurado que lo construía en su tierra, que había comprado a Juan Dorado

\section{Aroche}

Sus inmuebles hidráulicos aparecen únicamente en la pesquisa de 1497 (Tabla 13). Estuvieron situados en el Chanza (rivera de Chanza), del que se dice nacía en la fuente de Cortegana, desde donde discurre por el este y norte de Aroche, hacia el oeste, para servir de frontera con Portugal y desembocar en el Guadiana; en el arroyo de Los Cubos, hoy barranco de Los Cubos, que fluye hacia el Chanza al noreste de la villa; el Alcalaboza, hoy rivera de Alcalaboza o Peramora, que serpentea al sur de la localidad hasta confluir con el Chanza en la frontera portuguesa; y el arroyo de la Villa (barranco de la Villa), que se forma un poco más al sur de Aroche, la bordea por su lado oeste y sigue hacia el norte, para dar a unos $3 \mathrm{~km}$ en esa dirección con el curso del Chanza. Como vemos, y como para casi todos los casos anteriores, en Aroche sus ingenios se emplazaron en los cursos de agua que rodeaban la población casi por sus cuatro puntos cardinales. De ellos se dice en la citada pesquisa por los deponentes, que las tierras sobre las que estaban edificados no eran riveras caudales, sino arroyos, y no ríos, que molían solamente cuando llovía.

\section{Rivera de Alcalaboza}

Con ser una de las más importantes de la zona, apenas cuenta con un molino y un herido en esta relación, ambos sin función en ese momento. El primero, de Fernando Sandallo, erigido hacía un año, con vega, árboles y huerta, en su tierra, por estar ya por entonces estropeado. Como carecen de indicaciones topográficas, los he colocado de manera arbitraria en la Mapa 12. 
Mapa 11: Instalaciones de la Fuente del Gargallo, riveras de las fuentes de las Huertas y del Cincho y del arroyo del Álamo, en Higuera la Real y Fregenal de la Sierra (1497)

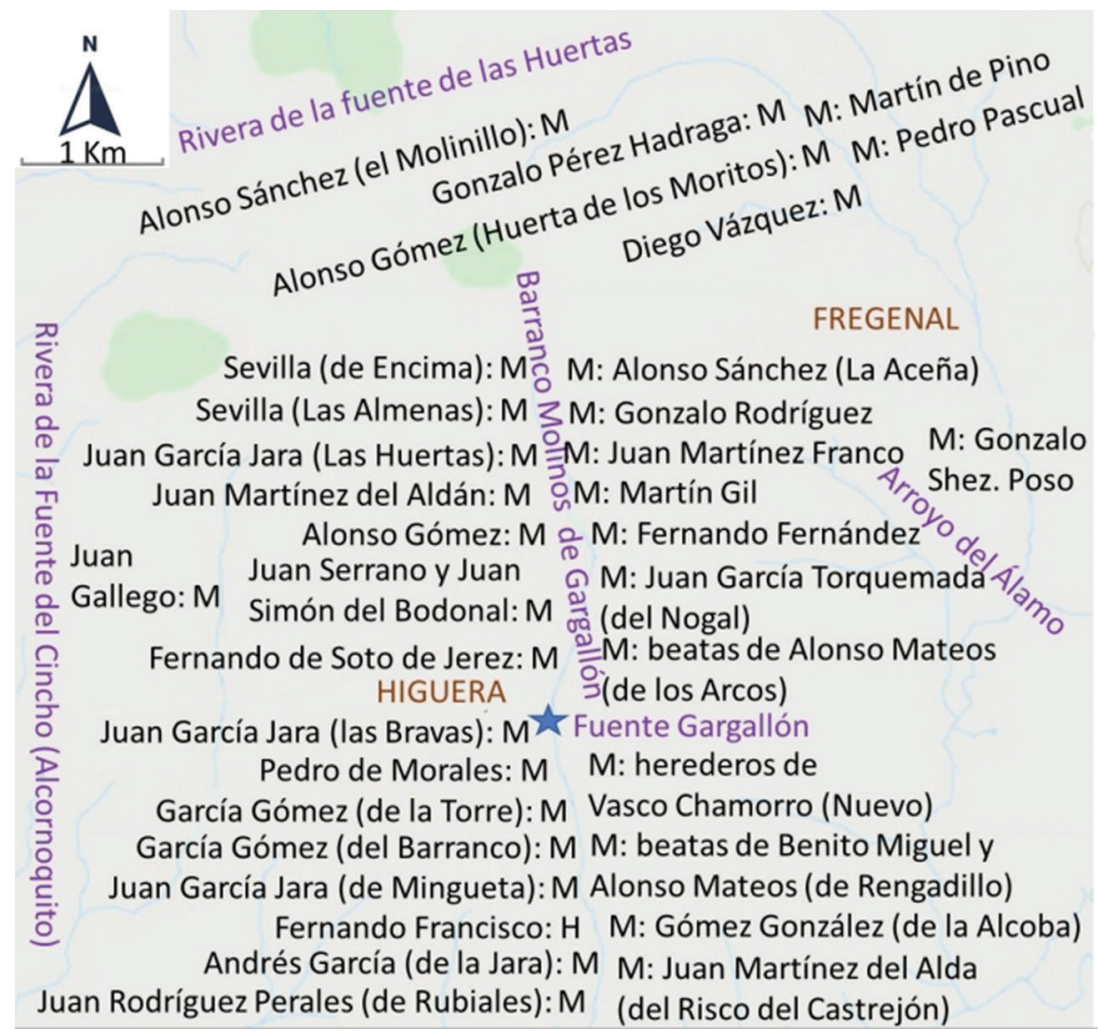

Fuente: AMS, Diversos, 725

Mapa 12: Instalaciones de las riveras de Chanza y Alcalaboza, en Aroche (1497)

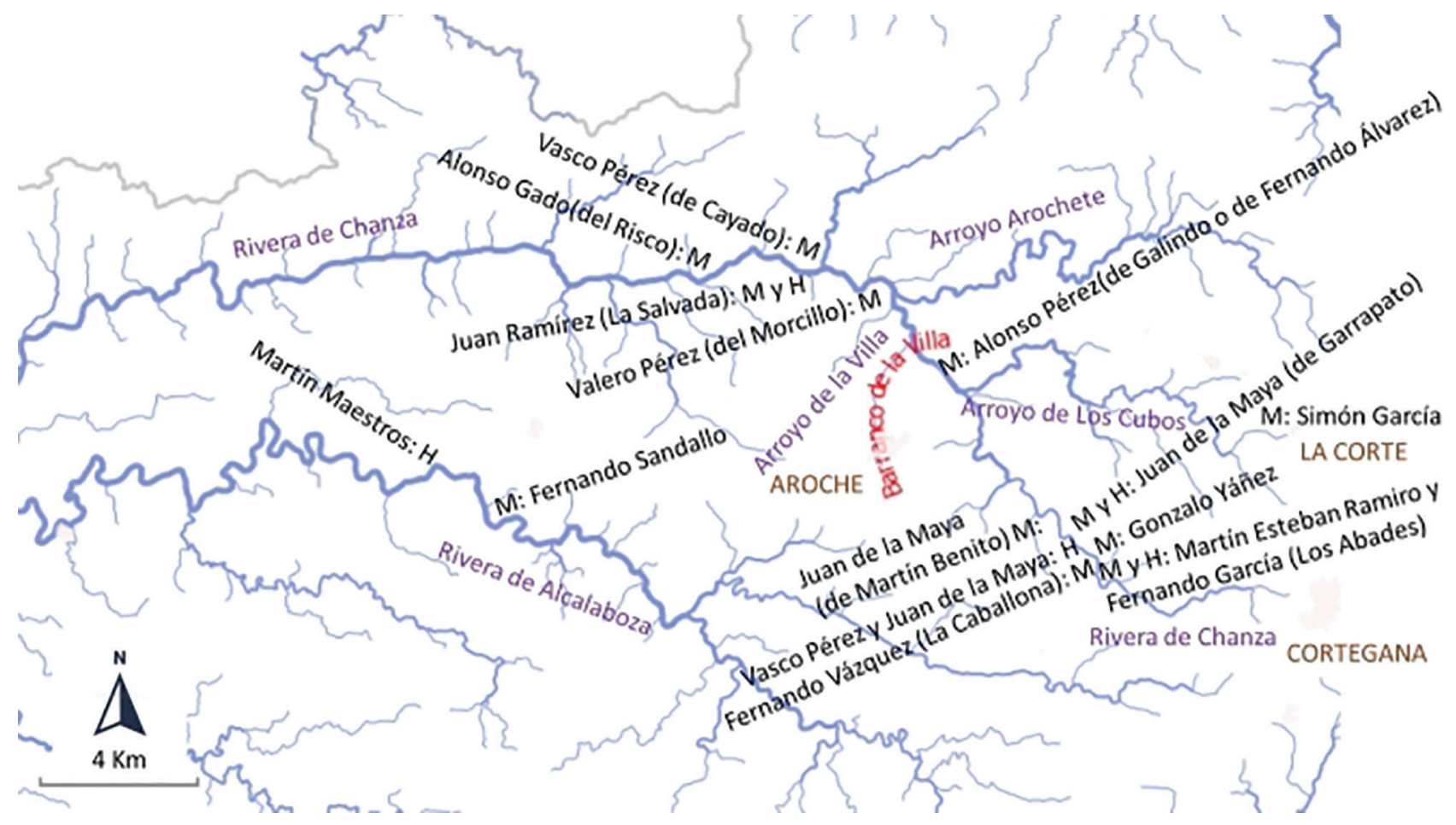

Fuente: AMS, Diversos, 720 
Tabla 13: Relación de inmuebles dedicados a actividades productivas que rentaban al almojarifazgo de Aroche (1497) y su tipología: molinos harineros (M), molinos batanes (B) y azudes o heridos $(\mathrm{H})$

\begin{tabular}{lc}
\hline \multicolumn{1}{c}{ Inmueble } & Nómina de los molinos del Chanza que nace de la fuente de Cortegana \\
\hline Molino de Martín Esteban Ramiro y Fernando García, alcalde, en la rivera de Chanza, se llama de los Abades & M \\
Molino de Fernando Vázquez, llamado de la Caballona, linda con el herido de los alcaides & M \\
Herido de Vasco Pérez y Juan de la Maya & $H$ \\
Molino de Juan de la Maya en dicha rivera, llamado de Garrapato & $H$ \\
Molino de Juan de la Maya, llamado de Martín Benito, linda con el anterior & M \\
Molino de Gonzalo Yáñez, hijo de Ruy González, linda con el de los alcaides & M \\
Molino de Alonso Pérez, de Galindo al que llaman de Fernando de Álvarez & M \\
Molino de Valero Pérez, que llaman del Morcillo, linda con el anterior & M \\
Molino de Vasco Pérez, alcaide, llamado de Cayado, linda con el anterior & $M$ \\
Molino de Juan Ramírez, llamado de la Salvada, linda con el anterior & $M$ \\
Molino de Alonso Gado, el herrero, llamado del Risco & $M$ \\
Molino de Simón García, en la Corte de la Nava, dehesa de la villa & $M$ \\
\hline
\end{tabular}

Molinos del arroyo de Los Cubos

Molino de Juan Sánchez, escribano, y Esteban Pérez, llamado de Fernando Vicente

Molino de Sancho Yáñez, hijo de Ruy González, llamado de Pedro Vázquez, linda con el anterior

Molino de Gonzalo Yáñez y Fernando González, llamado de María Ramos, linda con el anterior

Molino de Gómez Galero, llamado de la Masera, linda con el anterior

Molino de Gonzalo Galindo, llamado del Judío, linda con el anterior

Molino llamado de Diego Alonso Chavelas, lo posee él mismo, linda con el anterior

\begin{tabular}{|c|c|}
\hline \multicolumn{2}{|c|}{ Molinos del Alcalaboza } \\
\hline Molino de Fernando Sandallo, en su tierra entre la cabeza y el arroyo & M \\
\hline Herido de Martín Maestros & $\mathrm{H}$ \\
\hline \multicolumn{2}{|c|}{ Molinos del Arroyo de la Villa } \\
\hline Molino de Álvaro Rodríguez Jijas & M \\
\hline Molino llamado y propiedad de Valero Pérez, alcaide & M \\
\hline Molino llamado el de Pabramo & M \\
\hline Herido de Fernando González Conejo & $\mathrm{H}$ \\
\hline
\end{tabular}

Fuente: AMS, Diversos, 720

\section{Arroyo de Los Cubos}

Este afluente del Chanza por su margen derecha está formado por la confluencia de varios cauces menores. De todos sus inmuebles, molinos y heridos, se dice que eran contiguos, excepto del último, que hemos de suponer que, no obstante, también lo sería por la poca longitud de este barranco. A falta de indicaciones que hagan pensar lo contrario, como siempre, los he colocado en orden corriente abajo. Uno de ellos era posesión del concejo, y lo tenía Juan de la Maya, que sabemos contaba con otros inmuebles; como se indica que estaba en su tierra, con su vega y árboles, puede que fuese de su propiedad y del Concejo fuese el nombre del molino, por haber pertenecido antes al consistorio. La última instalación, de Alonso Pérez Lobato, y la cuarta empezando por el final, de Domingo Marqués, son dos heridos de los que se comenta que nunca molieron, el segundo porque se añade que no tenía 
mucha agua. Puede que, porque la desembocadura del arroyo en el Chanza es una zona llana, casi sin pendiente, de modo que allí el agua discurriría sin mucha fuerza; por lo que el resto de las instalaciones estarían curso arriba, con más pendiente, donde las he colocado en el Mapa 13.

\section{Arroyo de la Villa}

En este caso, tampoco se dice nada de dónde estuvieron ubicados sus tres molinos y un herido; que he emplazado en el Mapa 13 siguiendo el orden en el que aparecen, aguas abajo.

\section{Encinasola}

Pasemos, finalmente, a esta villa del confín de la actual provincia de Huelva, con Badajoz al norte y Portugal al oeste, que contó con ingenios hidráulicos principalmente en el Múrtigas, unos 28, antes de internarse en el país vecino; así como en su afluente, el Sillo, y en otro menos caudaloso, el arroyo del Cavá, enumerados en la Tabla 14.

\section{Múrtigas}

Algo antes de la confluencia del arroyo del Sillo, que lo separa del alfoz de Cumbres de San Bartolomé, con el Múrtigas, que lo atraviesa, comienza el término de Encinasola, donde se situaron la mayor parte de sus molinos, según la relación de 1497; en la que se dice que dicho río nacía cerca de Aracena, en término de Sevilla. Tales inmuebles, como en casos anteriores, según se dice en dicha pesquisa, estuvieron casi todos situados unos contiguos a otros, desde dicha confluencia de ambos cursos de agua en adelante. Así, el primero, de los Cárdenos (nombre que no queda claro por el mal estado del documento), lindaba con el de ¿Juan Brisedo? El segundo (de las ¿Huertas?), en poder de Vasco Fernández, no tenía vega ni isleta que tuviera por suyas, algo que se repite en casi todas las máquinas posteriores, que por ello serían del tipo aceña sobre el cauce fluvial. Al tercero, propiedad de Juan García y sus compañeros, se lo conocía como los Bocaches; mismo nombre que el cuarto, de Martín Vázquez y sus hijos.

Pues bien, a poco de penetrar en el actual término municipal marocho, el Múrtigas discurre por un paraje llamado Bocache, en su ribera derecha. De modo que, como he apuntado, el listado de 1497 se comenzó por el molino de la parte más alta del río, cerca de la desembocadura del Sillo, para proseguir aguas abajo en orden descendente. Pero, por si quedaran dudas al respecto, el quinto molino, llamado de Gonzalo Pérez, en ese momento era propiedad de Vasco Boza y sus compañeros, y un tercio del mismo de la iglesia de S. Andrés. Poco más abajo del anterior paraje de Bocache, y antes de llegar a otro cercano denominado Casas de Bocacho, se localiza un tercero conocido como Casas de Antón Boza. Resulta muy sorprendente la pervivencia de estos topónimos desde la baja Edad Media hasta nuestros días.

El decimotercero apunte es del molino de Ruy Pérez. Hacía 10 años que lo edificara Alonso de Flores, ¿alcalde?, que lo vendió a Ruy Pérez. Actualmente, poco antes de la frontera con Portugal, en los meandros del Múrtigas, en su margen derecha, hay un paraje llamado Casas de Flores, más abajo, otro conocido como Molino de Flores, y en el siguiente meandro están el Cortijo de Flores y la ermita de Nuestra Señora de Flores; entre estos dos últimos discurre el barranco Flores, que va a dar al Múrtigas. El decimoctavo se encontraba en el Castillejo, propiedad de Ruy García Bermejo, hecho tres años atrás. En el primero de los grandes meandros del río, dentro del término municipal de Encinasola, de nuevo en la ribera derecha, en su confluencia con los barrancos del Infierno y de Valdepegas, está el pico del Casti1lo. El decimonoveno es el molino llamado de Fernando Moreno, propiedad de Alonso García; con 40-41 años, edificado en tierras de Juan García y Gil García, por lo que se dio un tercio del molino a estos dueños del solar, y el otro tercio para el rey, por la inquisición. Curso abajo, tras los parajes de Flores antes vistos, podemos encontrar la Huerta del Moreno.

\section{Sillo}

Apenas tuvo tres inmuebles hidráulicos (Mapa 14), dado el poco recorrido de este arroyo por tierras marochas, y a que solamente su margen derecha perteneció a Encinasola, entre la desembocadura del barranco de las Sierpes en el mismo, y la del propio Sillo en el Múrtigas, pues la otra ribera era de Cumbres de San Bartolomé.

\section{Hoz de Cadaval}

Este curso de agua no se encuentra con ese nombre entre los del término de Encinasola. Como en la pesquisa de 1497 se dedica un epígrafe a los molinos de Cadaval, hemos de entender que se trata de la Hoz de Cadaval, 
Mapa 13: Instalaciones de los arroyos de Los Cubos y de la Villa, en Aroche (1497)

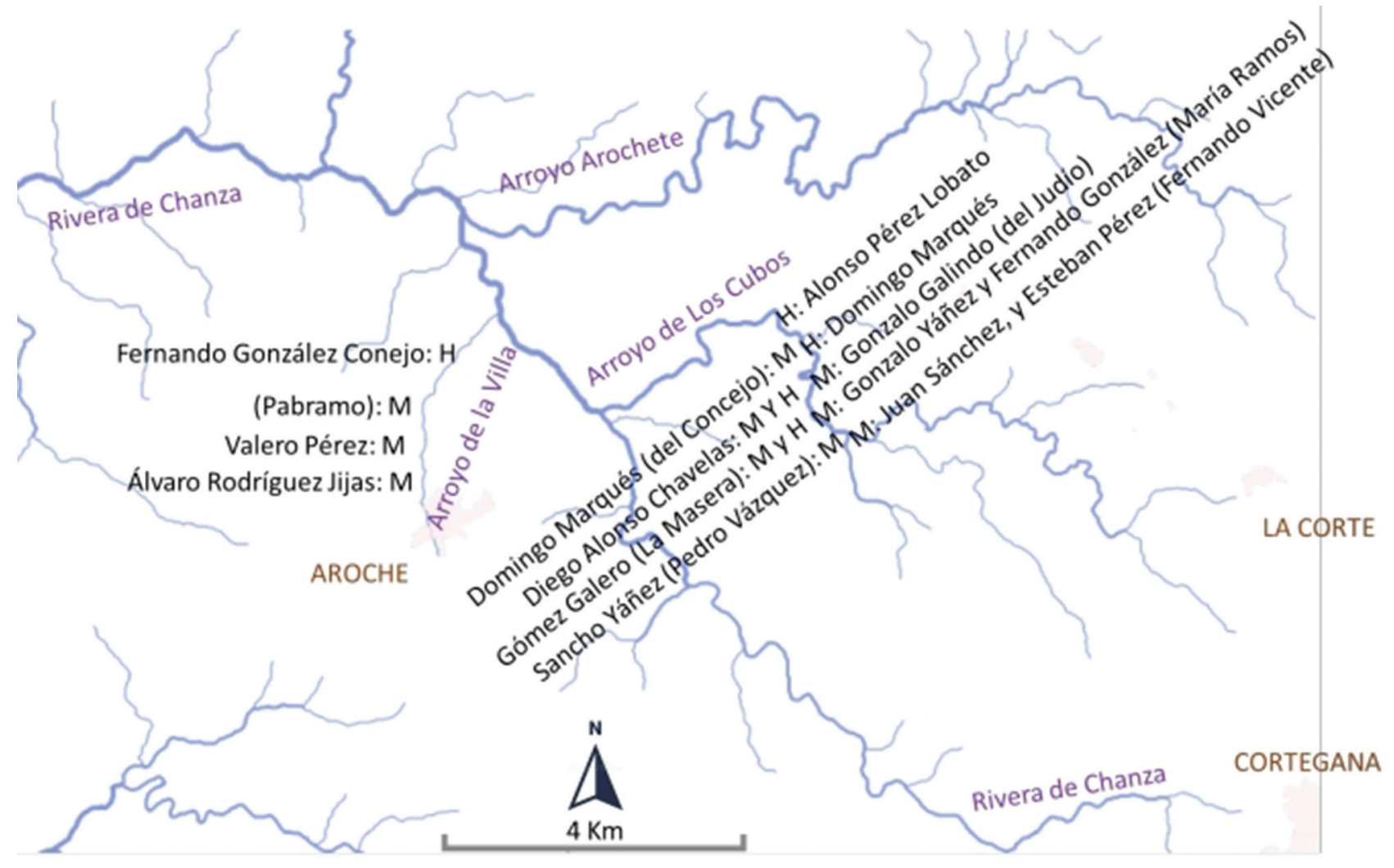

Fuente: AMS, Diversos, 720

mencionada en testimonios del siglo XIII sobre términos municipales ${ }^{32}$. En uno se la cita cercana a la propia Encinasola y a la fuente del Corcho; en el otro se dice que dicha hoz moría en el Múrtiga. Pues bien, al noreste de dicha localidad, cercano a ella, nace el arroyo del Cavá, o de la Caba, que va a desembocar al oeste en dicho río. Uno de los afluentes de este arroyo, por su margen izquierda, es el arroyo del Corcho. De modo que hemos de suponer que el actual arroyo del Cavá era la antigua hoz de Cadaval, topónimos ambos que guardan cierto parecido.

El primer molino de este arroyo recogido en la relación es el de Andrés Mora, que lo había erigido un año atrás en la dehesa del concejo. Al norte de Encinasola se halla el cerro Cavá, y a sus pies el actual embalse que lleva el nombre del pueblo, formado con las aguas del citado arroyo del Cavá. Más al norte, muy cercanas al pantano, se encuentran la Casa de las Dehesas y la Casa de la Dehesa, que toman su nombre del paraje situado al noreste de las mismas, llamado Dehesa Boyal; incluso el Cavá también recibe el nombre de arroyo de la Dehesa. Por lo que, una vez más, las relaciones refieren los edificios hidráulicos de forma ordenada y correlativa desde los cursos más altos aguas abajo. Así, el cuarto inmueble es el herido

\footnotetext{
32. García Fiz, 1998, 268-269.
}

de Vasco Fernández Moro, sito encima del charco de la Parra. Curso abajo del Cavá, cerca todavía de Encinasola, al noroeste de la misma, en su margen derecho, tenemos la sierra de la Parra, por cuyo piedemonte discurre dicho arrayo, al que obliga a formar varios meandros.

\section{Conclusión}

La buena dotación de recursos hídricos y el relieve montuoso de la Sierra de Aroche - actual comarca natural de la Sierra de Aracena y Picos de Aroche, más las tierras colindantes del sur de Badajoz-, permitieron a sus vecinos a finales del siglo XV la erección de unas 261 instalaciones molinares, entre molinos y presas y canales sin molino (o heridos). Casi todos ellos harineros, pero también ocho batanes de paños; en su mayor parte de eje vertical o de rodezno, aunque, asimismo, hubo algunas aceñas de eje horizontal.

Tales ingenios se dispusieron, en la mayoría de los casos, en barrancos, arroyos y riveras de escaso caudal, que solamente llevaban agua abundante en tiempo de lluvias; de ahí que, por necesidades técnicas, predominasen los artefactos de tipo vertical, con heridos. Si bien, igualmente, los edificaron en corrientes fluviales de mayor importancia y permanentes, como los ríos 
Tabla 14: Relación de inmuebles dedicados a actividades productivas, que rentaban al almojarifazgo de Encinasola (1497) y su tipología: molinos harineros (M), molinos batanes (B) y azudes o heridos $(\mathrm{H})$

Instalación

Molinos de la rivera de Múrtigas que nace cabo de Aracena, término de Sevilla

Molino llamado de los Cárdenos, linda con el de Juan Brisedo

Molino de Vasco Fernández, de las ¿Huertas?, linda con el de arriba

Molino de Juan García y sus compañeros, llamado de los Bocaches

Molino de Martín Vázquez y sus hijos, llamado de los Bocaches, linda con el anterior

Molino de Vasco Boza y sus compañeros, un tercio del mismo es de la iglesia de S. Andrés, llamado de Gonzalo Pérez

Molino llamado de Fernando González Castillos, lo poseen el antedicho y su hermano, linda con el anterior

Molino de Juan Rodríguez Pardo y sus compañeros, llamado de Pedro Miguel, entre la tierra de Juan Manuel, en la madre de la ribera que está entre la tierra de Juan Manuel y el realengo

Molino Domingo García y sus compañeros, llamado de la Vega, linda con el anterior

Molino de Bartolomé García Moriscote, su hijo, llamado del Moriscote, linda con el anterior

Molino de Alonso García Moreno y sus compañeros, linda con el anterior

Molino llamado de Juan Bernárdez y sus compañeros, linda con el anterior

Molino de Ruy Pérez, linda con el anterior

Molino de Juan García y sus compañeros, llamado de Gutiérrez, linda con el anterior

Molino de Francisco Vázquez, llamado ¿Nuevo?, linda con el anterior, en tierras del concejo

Molino que llaman de Antón Infante, linda con el anterior, en tierras del concejo

Molino de Andrés López y sus compañeros, llamado de los Francos, linda con el anterior

Molino Ruy García Bermejo, en el Castillejo, linda con el anterior

Molino de Alonso García, llamado de Fernando Moreno, linda con el anterior

Molino de Antón Pérez y sus compañeros, llamado del Abad, linda con el molino de García Álvarez

Molino de García Álvarez y sus compañeros, linda con el anterior

Molino llamado de la Merchanta, linda con el herido de Alonso Fernández

Herido de Alonso Fernández

Molino de Lorenzo Fernández, llamado el Puerto de Juan Martínez, linda con el anterior

Molino de Juan Rodríguez Maza, linda con el anterior

Herido de Alonso Rodríguez Bocacha

Herido de Gómez García

Herido de Juan Manuel, linda con el anterior

\section{Rivera de Sillo}

Molino de Juan García y de Gonzalo de Brea

Molino de la Decrimera, linda con el anterior

Herido de Juan Berto

Molinos del Cadaval (arroyo del Cavá)

Molino de Andrés Mora, en la dehesa del concejo

Molino de Juan Gómez

Molino de Bartolomé Moro

Molino de Juan Rodríguez Mazadas

Herido de Vasco Fernández Moro, encima del charco de la Parra, en su tierra

Fuente: AMS, Divervsos, 723 
Mapa 14: Instalaciones de las riveras de Múrtigas y Sillo, y de la Hoz de Cadaval, en Encinasola (1497)

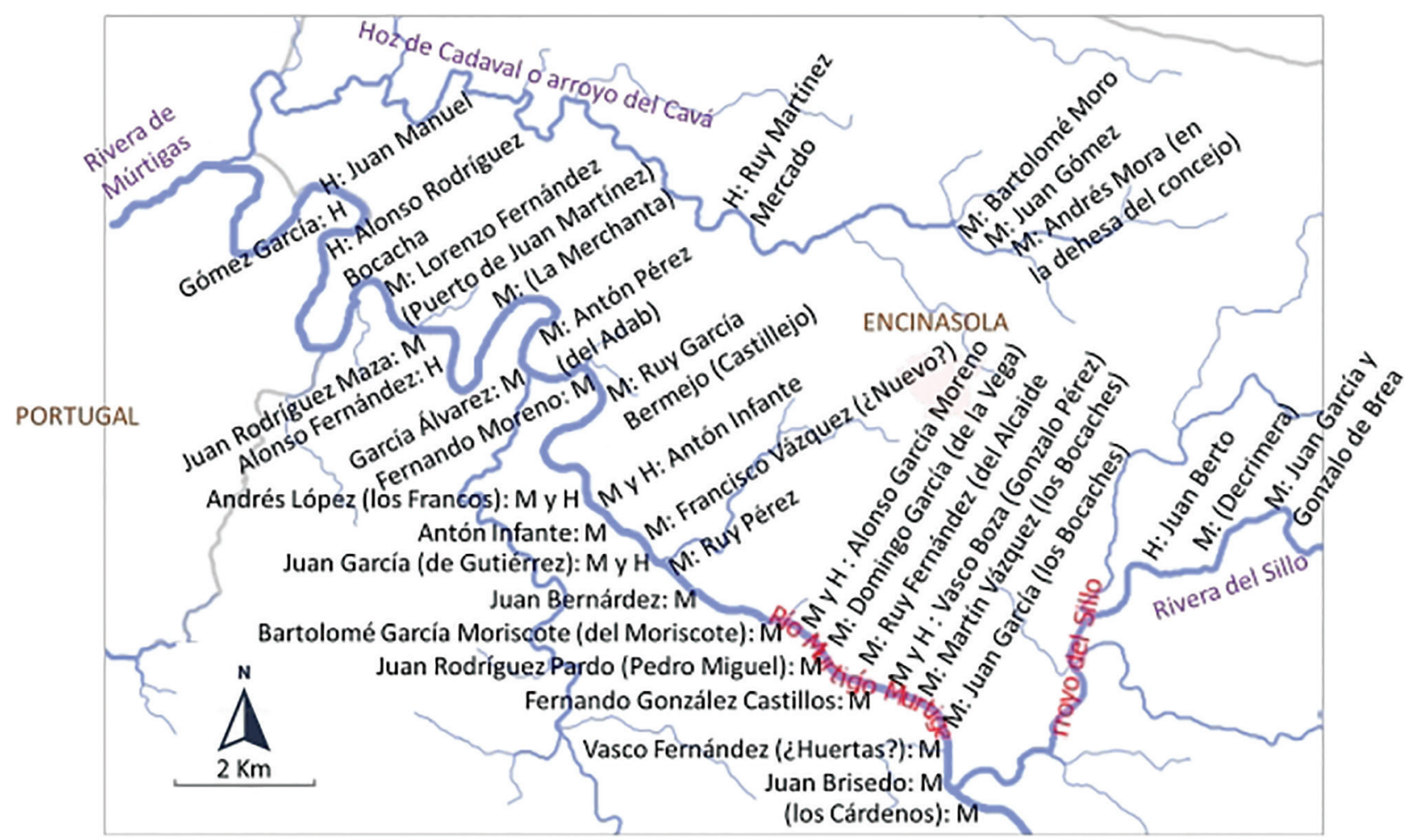

Fuente: AMS, Diversos, 723

Múrtigas, Chanza y Odiel, donde desembocaban los antedichos cursos menores, junto a la rivera de Huelva.

De modo que, en torno a estos cuatro últimos grandes valles fluviales, que drenan la comarca, se levantaron dos centenares y medio de inmuebles para aprovechar su potencia hidráulica, lo que dio lugar a un gran crecimiento económico, industrial y demográfico de la misma ${ }^{33}$. Ello supuso el aumento del tamaño de las principales villas de la tierra, pero también la proliferación de numerosas aldeas de nueva planta, donde se instalaron las gentes que iban a explotar estos recursos, hasta ese momento infrautilizados.

La ubicación sobre trece mapas de tales edificios, así como su localización concreta o relativa sobre los cursos de agua, me ha permitido reconstruir con gran precisión una de las redes molinares más extensas que se conocen para estas postrimerías de la Edad Media castellana. Lo que ha hecho posible comprobar que, tras más de 500 años, se han mantenido casi invariables los nombres de la mayor parte de tales cursos de agua y parajes. Algo totalmente sorprendente, que permitirá, en otros trabajos, estudiar la vinculación de los grupos humanos al territorio, pues muchos de los topónimos, ayer como hoy, están relacionados con apellidos familiares, o con las aldeas que se fundaron para la explotación de los recursos hidráulicos. También queda

33. Pérez-Embid Wamba, 1996. para otra ocasión realizar el análisis sobre quiénes fueron los titulares de estos molinos, así como sus relaciones con otras actividades económicas o su extracción social.

\section{Financiación}

Este trabajo ha sido realizado en el marco del proyecto HAR2017-83801-P "Política, instituciones y gobernanza de las villas y ciudades portuarias de la Europa Atlántica en la Baja Edad Media: análisis comparativo transnacional", del Ministerio de Economía, Industria y Competitividad.

\section{Fuentes}

Archivo Municipal de Sevilla (AMS), Diversos.

Los mapas son de elaboración propia, a partir de WMS Red Hidrográfica (tramos) de la cartografía de las Bases de Referencia Hidrológica de Andalucía:

http://www.juntadeandalucia.es/medioambiente/ site/rediam/menuitem.04dc44281e5d53cf8ca78ca73152 5ea0/?vgnextoid=a2d2431458a2b310VgnVCM100000132 5e50aRCRD\&vgnextchannel=cff74e7a1ac44410VgnVCM 2000000624e50aRCRD\&vgnextfmt=rediam\&lr=lang_es\#a partado52d2431458a2b310VgnVCM1000001325e50a 
Mapa topográfico ${ }^{34}$ :

http://contenido.ign.es/iberpix2/visor/

\section{BIBLIOGRAFÍA}

Bueno Hernández, F. 2012: "Las obras hidráulicas medievales en España. Una visión general", en Val Valdivieso, M.I. del y Bonachía Hernando, J.A. (coords.), Agua y sociedad en la Edad Media hispana, Granada, Universidad.

Córdoba de la Llave, R. 1990: La industria medieval del Córdoba, Córdoba, La Caja.

Córdoba de la Llave, R. 1993: "Molinos y batanes de la Córdoba medieval". Ifigea, 9, 37-56.

Córdoba de la Llave, R. 2002: "Sobre el origen y difusión de los Molinos de Regolfo". III Jornadas de Molinología, Murcia.

Luis Corral, F. 1996: "Feudalismo y molinos la posesión de aceñas en Zamora en el siglo XII". Studia Zamorensia, 3, 53-75.

García Fiz, F. 1998: "Política internacional, conflictos jurisdiccionales y construcciones militares a finales del siglo XIII en la sierra de Aroche: los castillos de Cumbres y Santa Olalla", Huelva en la Edad Media: reflexiones, aportaciones y nuevas perspectivas veinte años después, en Carriazo Rubio, J. L. y Miura Andrades, J. M. (eds.), Huelva en la Edad Media: reflexiones, aportaciones y nuevas perspectivas veinte años después, Huelva, Universidad de Huelva.

González Arce, J. D. 2020a: "Inmuebles de los pueblos de Sevilla dedicados a actividades económicas a finales del siglo XV", Archivo Hispalense, CIII(312-314), (en prensa).
González Arce, J. D. 2020b: Un patrimonio concejil ingente: el almojarifazgo de los pueblos de Sevilla (ss. XIII-XV), Murcia, Sociedad Española de Estudios Medievales.

Maluquer de Motes Bernet, J. 1982: "De nuevo sobre el molino hidráulico". Investigaciones Económicas, 18, 79-86.

Moreno Lázaro, J. 2018: "Negocio, tecnología e instituciones en la molienda del trigo en Castilla la Vieja y León a mediados del siglo XVIII". Investigaciones históricas: Época moderna y contemporánea, 38, 219-256, https://doi.org/10.24197/ihemc.38.2018.219-256

Oliver Narbona, M. 1983: Molinos harineros de agua, Alicante, Universidad.

Pérez Moreno, J. L. 2019: Los molinos de Alcalá de Guadaíra: Orígenes, expansión y ocaso (siglos XIII al XX), Alcalá de Guadaíra, Ayuntamiento.

Pérez-Embid Wamba, J. 1996: Aracena y su sierra. La formación de una comunidad andaluza (siglos XIII-XVIII), Huelva, Diputación.

Pérez-Embid Wamba, J. 1998: "Las Sierras de Aroche y Aracena: la formación de una unidad comarcal en el Reino de Sevilla durante la Baja Edad Media", en Carriazo Rubio, J.L. y Miura Andrades, J.M. (eds.), Huelva en la Edad Media: reflexiones, aportaciones y nuevas perspectivas veinte años después, Huelva, Universidad de Huelva.

Sánchez Jiménez, F.J. 2015: Estudio histórico-técnico de los molinos hidráulicos de Alcalá de Guadaíra, Tesis Doctoral, Sevilla.

\footnotetext{
34. De este mapa se han tomado, asimismo, la mayor parte de los topónimos y elementos del relieve.
} 